\title{
Gram-positive and Gram-negative Bacteria Share Common Principles to Coordinate Growth and the Cell Cycle at the Single-cell Level
}

\author{
John T. Sauls * Sarah E. Cox * \\ $\underset{\text { Quynh Do * Victoria Castillo * }}{\text { Suckjoon Jun } * \ddagger}$ \\ Zulfar Ghulam-Jelani * \\ Suckjoon Jun *
}

\begin{abstract}
Bacillus subtilis and Escherichia coli are evolutionarily divergent model organisms that have elucidated fundamental differences between Gram-positive and Gram-negative bacteria, respectively. Despite their differences in cell cycle control at the molecular level, both organisms follow the same phenomenological principle for cell size homeostasis known as the adder. We thus asked to what extent $B$. subtilis and $E$. coli share common physiological principles in coordinating growth and the cell cycle. To answer this question, we measured physiological parameters of $B$. subtilis under various steady-state growth conditions with and without translation inhibition at both population and single-cell level. These experiments revealed core shared physiological principles between $B$. subtilis and E. coli. Specifically, we show that both organisms maintain an invariant cell size per replication origin at initiation, with and without growth inhibition, and even during nutrient shifts at the single-cell level. Furthermore, both organisms also inherit the same "hierarchy" of physiological parameters ranked by their coefficient of variation. Based on these findings, we suggest that the basic coordination principles between growth and the cell cycle in bacteria may have been established in the very early stages of evolution.
\end{abstract}

\section{Introduction}

Our current understanding of fundamental, quantitative principles in bacterial physiology is largely based on studies of Escherichia coli and Salmonella typhimurium (see Jun et al. ${ }^{1}$ for a review of the history and recent progress). Several of these principles have been presented in the form of 'growth laws' ${ }^{1}$. For example, the 'growth law of cell size' states that the average cell size increases exponentially with respect to the nutrient-imposed growth rate ${ }^{2}$. This principle has been extended to the 'growth law of unit cells', which allows prediction of the average cell size based on the growth rate and the cell cycle duration for any steady-state growth condition ${ }^{3}$.

Gram-positive B. subtilis is distinct from Gram-negative $E$. coli at the genetic, molecular, and regulatory level ${ }^{4}$. However, despite their evolutionary divergence, B. subtilis and $E$. coli follow the same phenomenological principle of cellsize homeostasis known as the adder principle ${ }^{5,6}$. Furthermore, both organisms share the identical mechanistic origin of the adder principle, namely, a molecular threshold for division proteins and their balanced biosynthesis during growth ${ }^{7}$. Based on these findings, we wanted to know to what extent B. subtilis and E. coli coordinate growth, size, and cell cycle in the same manner. A shared coordination framework would imply that, despite phylogenetic and molecular diversity, physiological regulation in bacteria is functionally conserved.

In order to create a full complement of data necessary for comparative analysis, we measured the growth and cell cycle parameters of $B$. subtilis at both the population and single-cell level under a wide range of conditions.

Previous population-level studies have found that $B$. subtilis, like E. coli, initiates replication at a fixed mass, es-

*Department of Physics, University of California San Diego, La Jolla, California, 92093, USA * Section of Molecular Biology, Division of Biology, University of California San Diego, La Jolla, California, 92093, USA tablishing a regulatory bridge between cell size and cell cycle control ${ }^{8-10}$. We extended this avenue with single-cell methods to precisely measure the cell cycle parameters in individual $B$. subtilis cells across conditions ${ }^{7,11}$. These results showed that the initiation size is constant not only in steady-state conditions, but also during nutrient shifts between two steady-state conditions. This strongly supports a threshold model for initiation in both steady and dynamic environments ${ }^{3,7,12,13}$.

The single-cell approach also allowed us to compare the relative variability of all growth and cell cycle parameters both between conditions and between species. These measurements reveal a strikingly similar hierarchy of physiological parameters between B. subtilis and E. coli in terms of tightness of their control.

The richness of our quantitative physiological data generated in B. subtilis is comparable to that in E. coli, providing key evidence that $B$. subtilis and E. coli share core phenomenological and quantitative principles that govern their physiology, thereby providing a unified picture of bacterial growth, size, and cell cycle coordination.

\section{Results and discussion}

\section{Ensuring steady-state growth in B. subtilis}

Maintaining a steady-state growth is essential for reproducible measurements of the physiological state of the cell ${ }^{1}$. In steady-state growth, the total biomass of the culture increases exponentially with time and protein biosynthesis is balanced with the total biomass increase. That is, the protein production rate is the same as the growth rate of the cell. As a result, average protein concentrations are constant, whereas the total amount of proteins increases in proportion to the cell volume. This constant concentration and proportional increase also applies to other macromolecules such as DNA, RNA, phospholipids, and the cell wall. 
A Turbidostat steady-state culture vial and
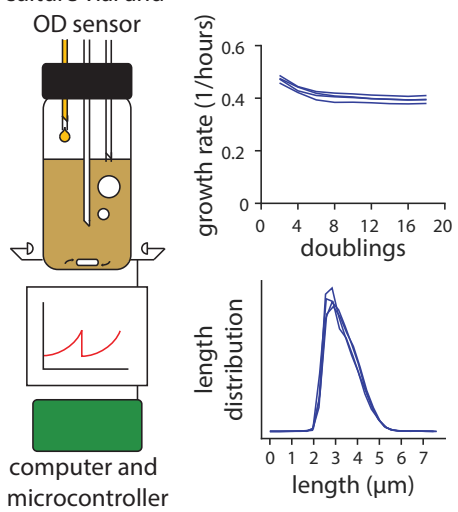

microcontroller

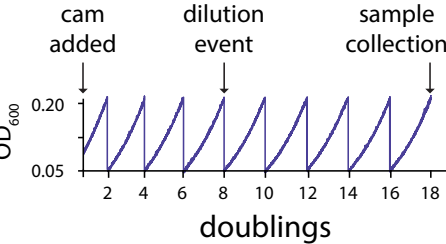

\section{B Growth conditions}

growth media

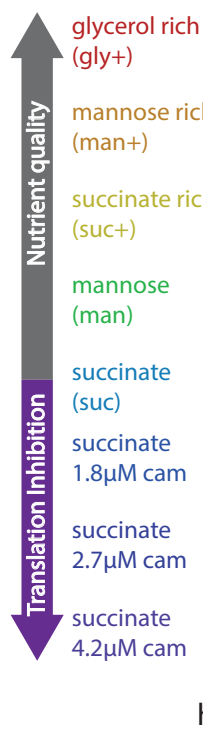

growth curves $\tau(\min )$ image
C Mother machine steady-state

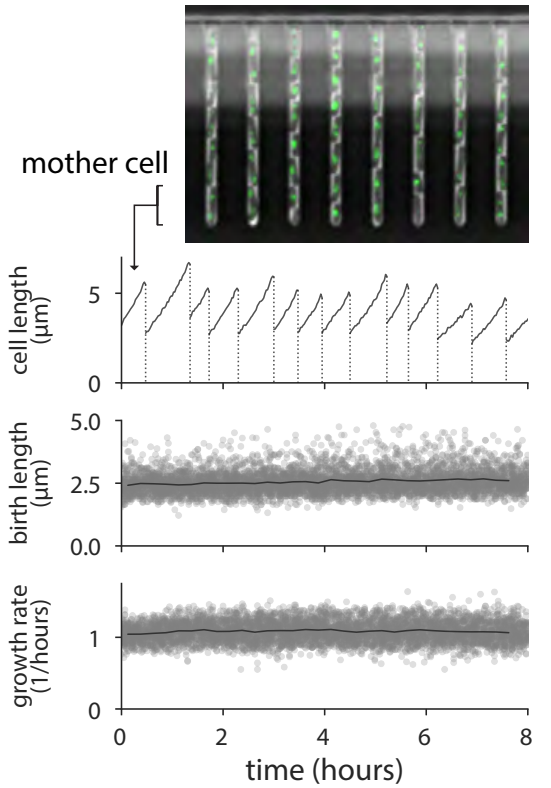

Figure 1: Population and single-cell methods to achieve steady-state growth. (A) Turbidostat experimental method and validation. Top left: In the multiplex turbidostat vial, the culture volume was maintained constant and cell concentration was monitored and adjusted automatically by infusing fresh medium. Aerobic conditions were ensured via bubbling and stirring. Top right: growth rate measurements were consistent between 5 and 20 doublings and cell length distributions were reproducible at sample collection. Data shown is from 4 repeats in succinate with $2.7 \mu \mathrm{M}$ chloramphenicol (cam). Bottom: A representative growth curve showing the timing of the addition of chloramphenicol, dilution events, and sample collection. Each dilution occurred when the culture reached $\mathrm{OD}_{600} 0.2$ and was diluted to 0.05 , allowing for two doublings during the growth interval. (B) Overview of population growth conditions and measurements. Growth media and their abbreviations for 5 different nutrient conditions, all of which are based on $\mathrm{S} 7_{50}$. Glycerol rich, mannose, and succinate were selected for translation inhibition experiments (succinate shown here). Representative growth curves (final 8 doublings), average doubling time $\tau$, and representative crops of images used for population sizing shown for each condition. (C) Single-cell experiments with the mother machine. Representative image showing cell-containing traps. Fluorescent signal is DnaN-mGFPmut2 (Figure 3, Materials and methods). The growth in length (black lines) and division (dotted vertical lines) of a single mother cell is shown over 8 hours. Average birth length and growth rate (solid grey lines) of the single-cell measurements (grey scatter points) are in steady-state over the course of the experiment. Data shown is from mannose. Additional measurements for all conditions are presented in Extended Figure 1-1.

To achieve steady-state measurements in B. subtilis, we grew and monitored cells over many generations using a multiplex turbidostat that we previously used for $E$. coli ${ }^{3}$ (Figure 1A). For both population and single-cell methods, we began cultures from single colonies and pre-cultured cells using appropriate batch methods before transferring to continuous culture set-ups (Materials and methods). We ensured pre-cultures did not enter stationary phase to avoid sporulation. We used a B. subtilis strain which was non-motile and non-biofilm forming to facilitate single cell-size measurements. This was necessary because $B$. subtilis exhibits a temporal chaining phenotype, particularly in faster growth conditions ${ }^{14,15}$. During chaining, cells are physically connected yet their cytoplasms are compartmentalized, obfuscating a definition of division ${ }^{16,17}$. Our strain contained a genetic modification to abolish cell chaining, ensuring that cell separation coincided with septation ${ }^{18}$ (Materials and methods).

To measure how long it takes for B. subtilis to reach physiological steady state, we measured growth rate continuously during time course experiments using our multiplex turbidostat. Growth rate generally stabilized after 6 generations, and the cell size distribution was reproducible (Figure 1A). However, to be certain of steady-state growth, we typically waited for at least 14 doublings before sample collection in all our subsequent experiments. At collection, we split the culture for qPCR marker frequency and cell size measurement (see

\section{Table 5 for experimental conditions).}

For single-cell measurements, we used the microfluidic mother machine to collect phase contrast and fluorescent timelapse images for at least 10 generations ${ }^{7,19}$ (Figure 1C). After analyzing all cell lives, we limited our data to the time interval in which all measured parameters equilibrated (Extended Figure 1-1). A typical experiment produced data for around 2,500 cells (see Table 6 for experimental conditions).

\section{Growth law of cell size: $B$. subtilis size shows a positive but not exponential dependence on the nutrient-imposed growth rate}

A foundational observation by Schaechter, Maaløe, and Kjeldgaard showed that the average cell size in E. coli increases exponentially with respect to the nutrient-imposed growth rate $^{2}$. Previously, we investigated this 'growth law of cell size' in $E$. coli under various growth and cell cycle inhibition, and showed that the exponential relationship was a special case wherein the growth rate was the only experimental variable ${ }^{3}$. In B. subtilis, the Levin lab recently revisited the relationship between size and the nutrient-imposed growth rate, and found that the average cell size in $B$. subtilis increased with the growth rate at the population level ${ }^{20}$.

We extended our efforts in E. coli to B. subtilis. Using the multiplex turbidostat, we grew cells in 5 nutrient conditions 
A Cell size versus growth rate

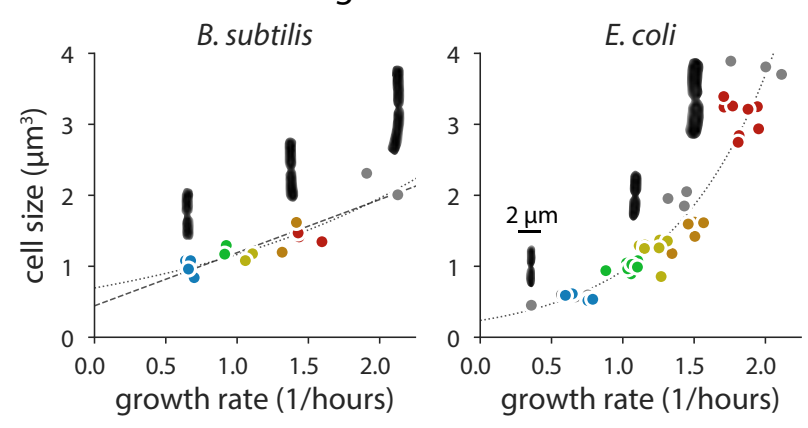

B C period versus growth rate

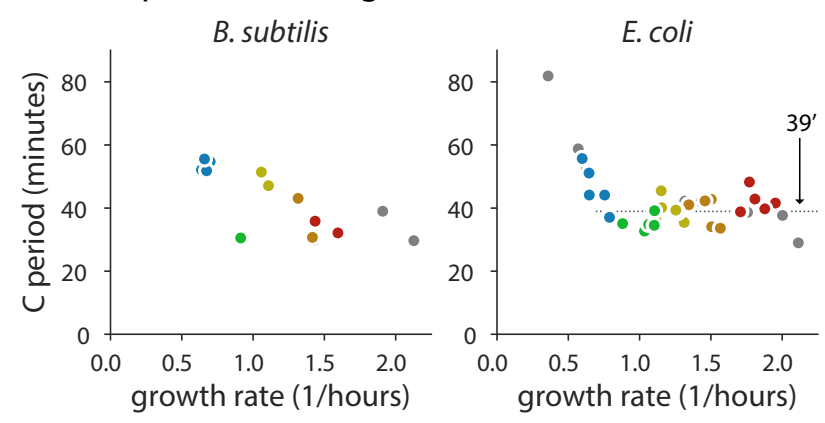

Figure 2: Population cell size and $\mathbf{C}$ period measurements in $\boldsymbol{B}$. subtilis and $\boldsymbol{E}$. coli. (A) Cell size increases with respect to growth rate in B. subtilis and E. coli under nutrient limitation. For B. subtilis, the relationship is not clearly exponential as it is for $E$. coli (dotted lines are linear regression fits of logarithm transformed data, dashed line is a linear regression fit). Representative images of cells during division show change in aspect ratio as a function of growth rate. Length and width measurements presented in Extended Figure 2-1. (B) $\mathrm{C}$ period measurements with respect to growth rate in $B$. subtilis and $E$. coli under nutrient limitation. For $E$. coli, C is approximately constant at 39 minutes (horizontal dotted line) for doubling times faster than 60 minutes $(\lambda=0.69)$. That constancy is less clear for B. subtilis, though single-cell data shows that $\mathrm{C}+\mathrm{D}$ is proportional to generation time (Extended Figure 4-1). B. subtilis growth media are colored as in Figure 1B with additional LB data in grey. E. coli data is previously published work ${ }^{3}$; Red is synthetic rich, orange is glucose with 12 amino acids, yellow is glucose with 6 amino acids, green is glucose, and blue is glycerol, with additional conditions in grey.

with doubling times ranging between 28 and 62 minutes (Figure 1B, Materials and methods; Table 5). Here, we use size interchangeably with volume, and consider volume to be proportional to dry mass ${ }^{21}$.

Figure 2A shows the average cell size versus growth rate for the 5 different growth conditions. As expected, the average cell size increased with growth rate. However, the exponential dependence observed for $E$. coli was less clear in B. subtilis. This discrepancy in B. subtilis could be due to changes in the duration of replication ( $\mathrm{C}$ period) and cell division ( $\mathrm{D}$ period) in different nutrient conditions ${ }^{3}$.

We thus measured the population average $C$ period of $B$. subtilis employing qPCR marker frequency analysis ${ }^{3,10,22}$. Both species exhibited a similar maximum replication speed (approximately 40 minutes for $\mathrm{C}$ period), but our data indeed do not indicate $\mathrm{C}$ period is strictly constant in fast growth (Figure 2B).

Unfortunately, despite extensive efforts, we were unable to reliably measure the D period in B. subtilis from the population samples as we had done previously for $E$. coli ${ }^{3}$. The main issue was consistency of fluorescence labeling of the DNA required for flow or image cytometry. Our results were variable from experiment to experiment, and protocol to protocol. We therefore concluded that the measurement of D period using population methods is not as reliable as needed to test the growth law of cell size in $B$. subtilis, a cautionary reminder in interpreting previous measurements in $B$. subtilis. For these reasons, we set out to measure the B. subtilis cell cycle explicitly at the single-cell level.

\section{Single-cell determination of cell cycle parame- ters in B. subtilis}

We employed a functional replisome protein fused with a fluorescent marker, DnaN-mGFPmut2, to measure cell cycle progression in single cells $\mathrm{s}^{7,23}$ (Materials and methods). In B. subtilis, the replisomes from the two replication forks of a replicating chromosome are often colocalized, thus most foci represent a pair of replisomes ${ }^{24}$.

Figure $3 \mathrm{~A}$ and $\mathrm{B}$ show representative cells from two growth conditions, succinate and glycerol rich, respectively. In the slower growth condition (succinate), cells were normally born with one replicating chromosome. Replication initiation begins synchronously in the mother cell for two chromosomes. At that time, the origins are located towards the cell poles. Replication proceeds through cell division, at which point the replication forks reside near the midcell of the newly born cell. Chromosome segregation is concurrent with replication. By the time the replication forks reach the terminus region, which is still at the midcell, the previously duplicated origins have already migrated to the cell poles ${ }^{25}$.

While overlapping cell cycles are common even at slower growth, cells rarely exhibit multifork replication. Multifork replication indicates initiation begins before the previous termination event completes. Instead, B. subtilis normally initiates when the cell contains complete, homologous chromosomes where the copy number is a power of two. In fact, replication initiation often proceeds immediately after the previous termination event. This may be due to the role of YabA in B. subtilis replication initiation control, which ties DnaA activity to DnaN availability ${ }^{26,27}$. Comparatively, multifork replication is common in E. coli, where Hda is thought to play a similar but mechanistically distinct role in reducing initiation potential during ongoing replication ${ }^{7,28}$.

In faster growth conditions (glycerol rich), cells are often born with two replicating chromosomes. However, the relative variability between division size and $\mathrm{C}+\mathrm{D}$ was greater in this rich condition. This means that a substantial fraction of the population were still born with one replicating chromosome (Extended Figure 6-2). Moreover, transient filamentation and asymmetrical septation are more common in fast growth conditions, leading to cells born with a number of replicating chromosomes which are not a power of two. 
bioRxiv preprint doi: https://doi.org/10.1101/726596; this version posted August 6, 2019. The copyright holder for this preprint (which was not certified by peer review) is the author/funder. All rights reserved. No reuse allowed without permission.

A Succinate

$\tau=62$ minutes, 1 overlapping cell cycle

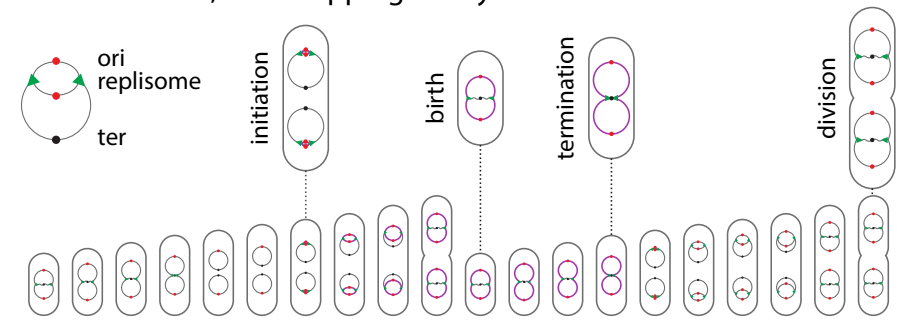

DnaN-mGFPmut2
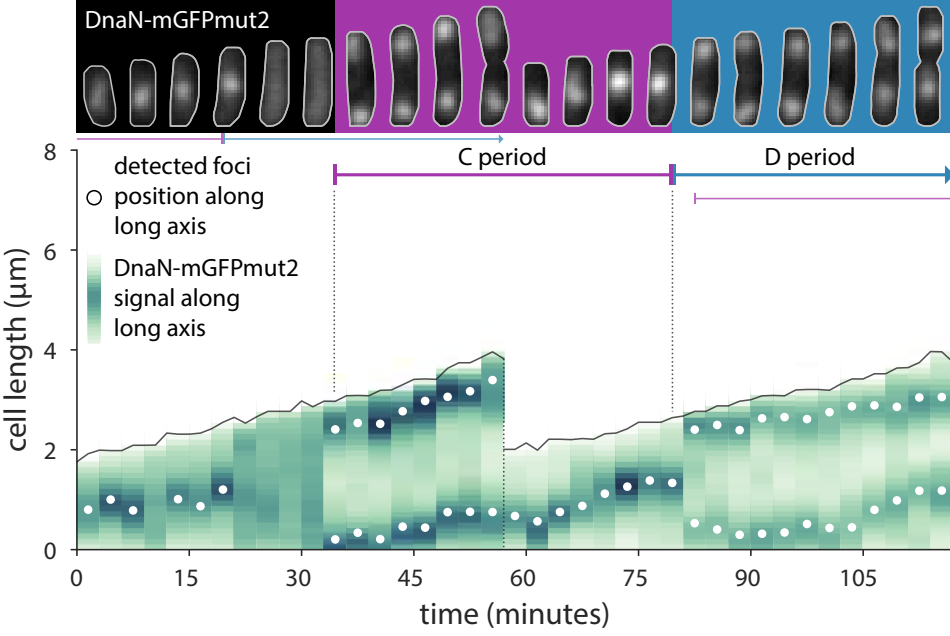

B Glycerol rich

$\tau=25$ minutes, 2 overlapping cell cycles
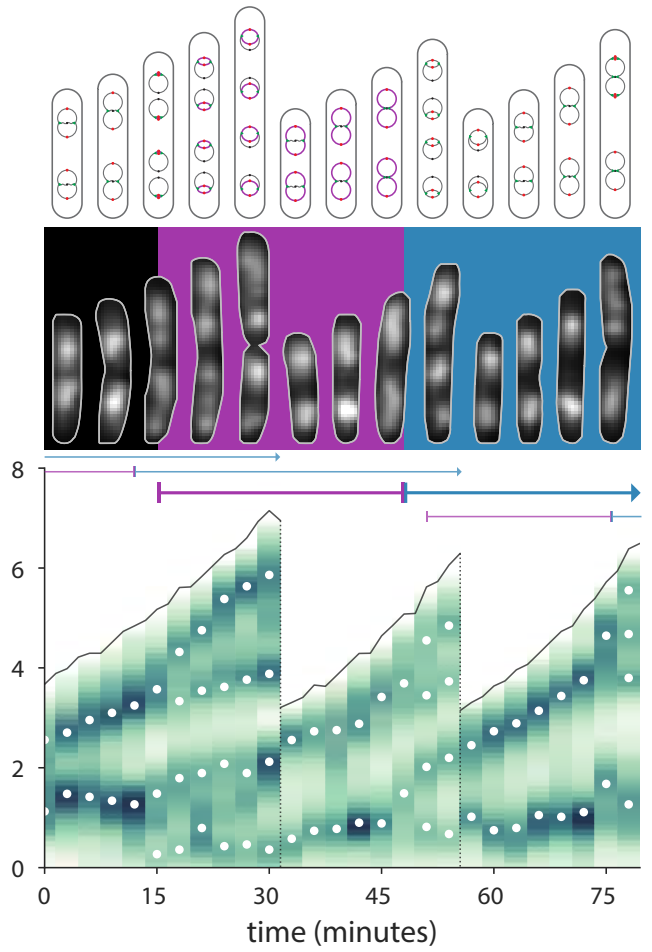

C Number of replisomes aligned to length across all cells in one growth condition

Succinate

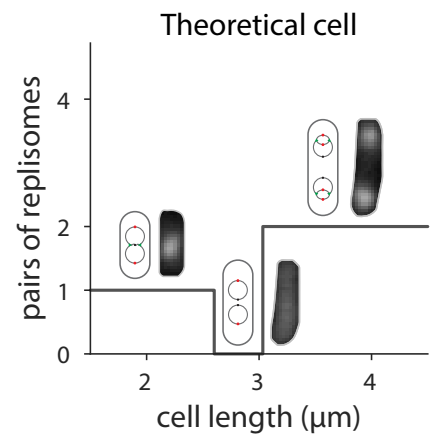

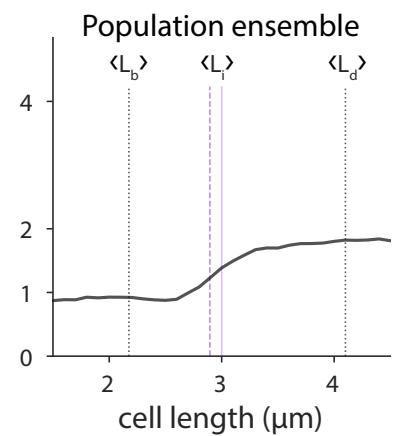

Glycerol rich

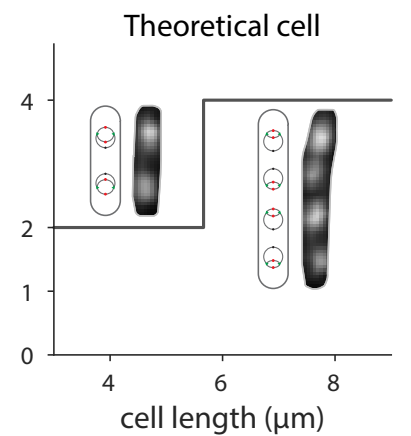

Population ensemble

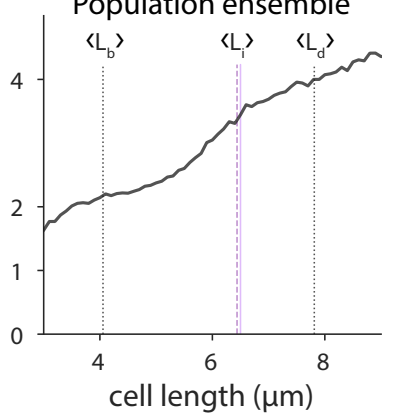

Figure 3: Single-cell growth and cell cycle progression in B. subtilis. (A) Typical cell cycle progression of B. subtilis in slower growth media. All panels show the same two cells. Top: Chromosome configuration and key cell events. Middle: Fluorescent images of DnaN-mGFPmut signal. Grey outlines are from the segmented phase contrast image. Purple and blue backgrounds indicate C and D periods corresponding to the second division. Bottom: Processed image data represented as a cell lineage trace. Cell length and division are indicated by the solid and dotted black lines, respectively. Vertical green bars are the DnaN-mGFPmut2 signal summed along the long axis of the cell, with white circles showing foci position. The single-cell initiation size, C period, and D period, are determined manually from these traces. (B) Typical cell cycle progression of B. subtilis in faster growth media. (C) Ensemble method to determine cell cycle parameters. Left: In succinate, a theoretical cell is born with one pair of replisomes. It may briefly contain no active replisomes upon termination, and then contain two pairs of replisomes as the two complete chromosomes begin replication. The length at which the number of replisome pairs increases corresponds to the initiation size. Across all cells, the average number of replisome pairs transitions from one to two at the population's initiation size. The average initiation length $\left\langle\mathrm{L}_{\mathrm{i}}\right\rangle$ as determined from the cell traces (dashed purple line) agrees with the ensemble estimate (solid purple line). The average birth $\left\langle\mathrm{L}_{\mathrm{b}}\right\rangle$ and division length $\left\langle\mathrm{L}_{\mathrm{d}}\right\rangle$ of the population are shown as dotted vertical lines. Right: In glycerol rich, cells transition from two to four pairs of replisomes. Ensembles for all conditions are available in Extended Figure 3-1.

\section{Complementary, ensemble determination of cell cycle parameters in $\boldsymbol{B}$. subtilis}

The main advantage of the single-cell approach is that it allows for direct comparison of the relationships between growth parameters, providing mechanistic insights 6 . However, it can be difficult to determine the cell cycle parameters manually, particularly when the foci are clumped or the signal is weak. This is especially true in faster growth conditions. To ensure an unbiased analysis of the cell cycle, we also employed an "ensemble method" to extract cell cycle parameters $^{11}$ (Figure 3C). We used the foci count at a given size as a proxy for the replication state (Materials and methods). This method produces data similar to the original schematics used by Helmstetter and Cooper when first elucidating the $E$. 
A Single-cell initiation and division size

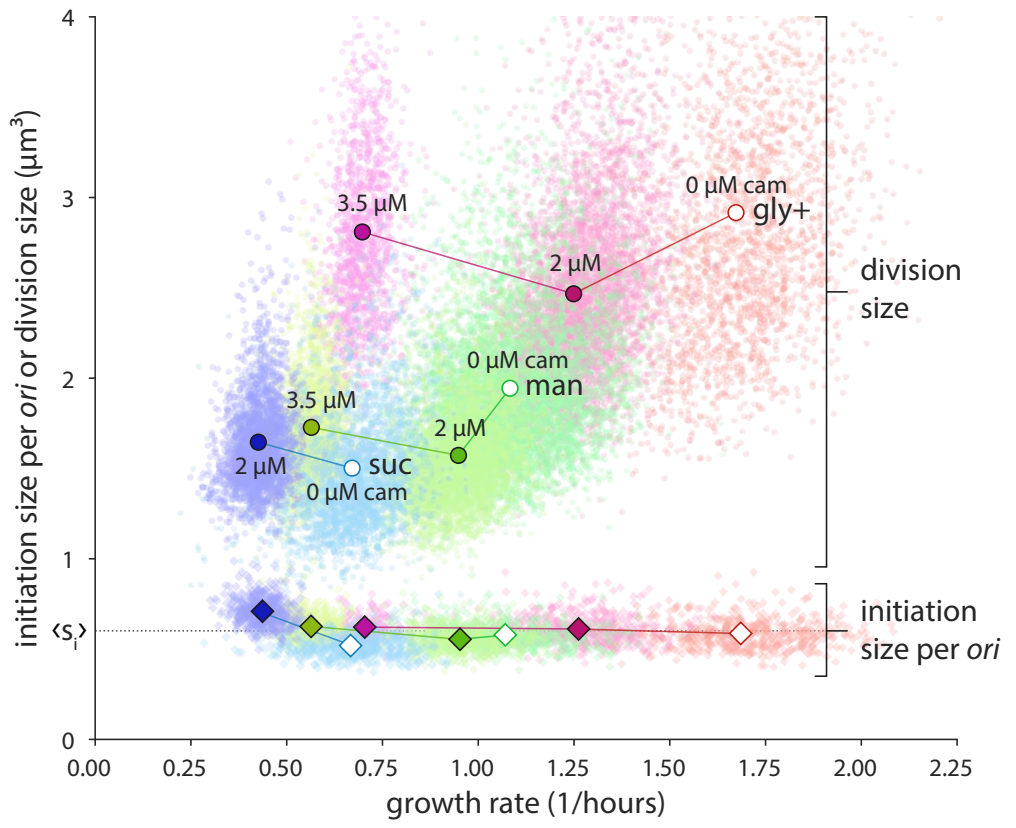

B Change in initiation size and $C+D$

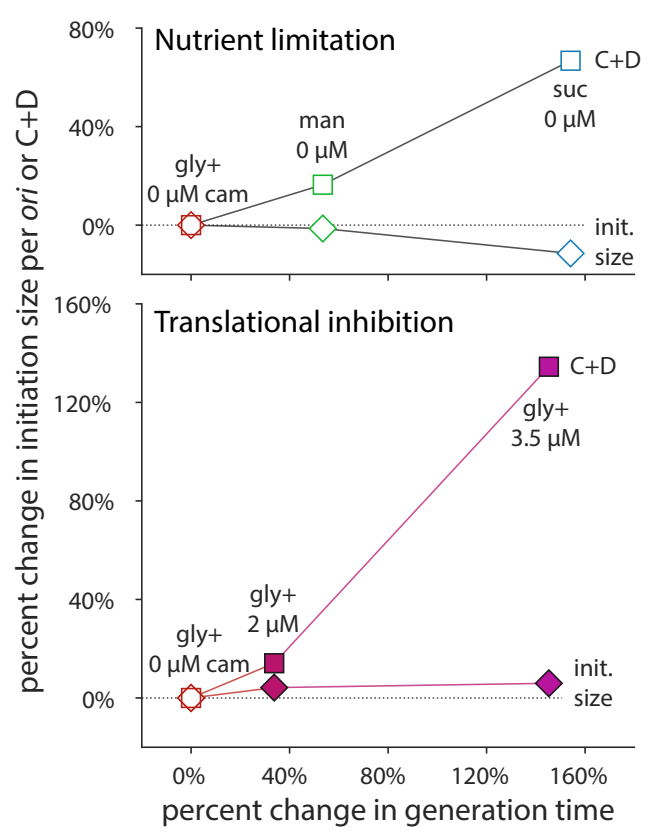

Figure 4: Initiation size is invariant in B. subtilis during steady-state growth. (A) Single-cell initiation size per ori $\mathrm{s}_{\mathrm{i}}$ is condition independent. Division size (circles) changes dramatically under both nutrient limitation and translational inhibition. The corresponding initiation size per ori (diamonds) collapses onto a constant value, $\left\langle\mathrm{s}_{\mathrm{i}}\right\rangle$, across all conditions (dotted horizontal black line). This holds for both single cells (scatter points) and population averages (solid symbols). Growth media are colored as in Figure 1B with the amount of chloramphenicol indicated $(0 \mu \mathrm{M}$ chloramphenicol with empty symbols, lines connect the same growth media with and without chloramphenicol). (B) $\mathrm{C}+\mathrm{D}$ is condition dependent and increases with generation time. Top: Increase in generation time under nutrient limitation causes an increase in the population average $\mathrm{C}+\mathrm{D}$ (squares) while initiation size minimally changes. Bottom: A similar pattern is seen under translational inhibition. For both plots, measured parameters are compared to the fastest growth condition. Single-cell C+D data presented in Extended Figure 4-1 and Extended Figure 6-2.

coli cell cycle ch $^{29}$

For all but the slowest growth conditions, the measured average number of foci monotonically increases because initiation almost immediately follows termination as discussed above. Unlike a theoretical single cell, the ensemble plots do not display a strict step-like behavior; we interpret this as variability in the initiation size. Ensemble plots for all conditions, along with the foci localization patterns, are presented in Extended Figure 3-1. This measurement is in good agreement with the average initiation size as measured from individual cells. We used these complementary methods to test whether the initiation size is invariant in B. subtilis as in E. coli ${ }^{3}$.

\section{Invariance of initiation size: $B$. subtilis initiates at a fixed cell size per ori}

In E. coli and S. typhimurium, the concept of a conserved initiation size was first explained by Donachie as a consequence of the growth law of cell size and the constant $\mathrm{C}+\mathrm{D}^{2,8,29}$. The upshot is that, at a fixed size per origin (ori), all origins of replication fire simultaneously. Recent highthroughput works at both single-cell and population levels have conclusively shown that the early insight by Donachie was correct ${ }^{3,7,11}$. In fact, the initiation size per ori is invariant not only across nutrient conditions, but also under antibiotic inhibition and genetic perturbations ${ }^{3}$.

The constancy of initiation size in B. subtilis has previously been tested by several groups at the population level under nutrient limitation conditions $\mathrm{s}^{9,10,30}$. We further measured the initiation size using single-cell methods under nutrient limitation and translational inhibition. We found that the initiation size per ori in B. subtilis is indeed invariant across conditions, even for individual cells (Figure 4A).

This constant initiation size is in stark contrast to the varying $\mathrm{C}$ period under different growth conditions (Extended Figure 4-1A). In fact, initiation size is one of the least variable physiological parameters along with septum position and width (Extended Figure 6-2). The single-cell approach also allowed us to measure the correlations between all growth and cell cycle parameters. The initiation size is only weakly correlated with other measured parameters (Extended Figure 6-3).

These observations are consistent with a threshold model for replication initiation ${ }^{3,7,31}$. Within that framework, initiator molecules accumulate proportional to the growth rate. This mechanism is enacted in single cells and is in turn apparent at the population level.

\section{Initiation size is invariant even during nutrient shifts at the single-cell level}

Because the constant initiation size was implemented by individual cells in the previous steady-state experiments, we wondered how cells would behave in a changing environment. Nutrient shift experiments have provided important insight into the coordination of biosynthesis and the cell cy$\mathrm{cle}^{32-34}$. We revisited this paradigm at the single-cell level, 


\section{A Nutrient shift-down and single-cell behavior}

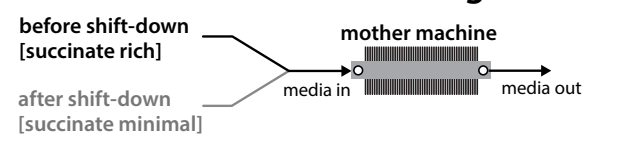

$\rightarrow$ nutrient shift-down

growth and initiation arrest

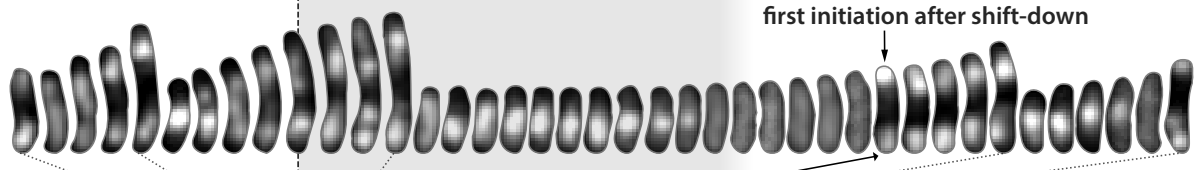
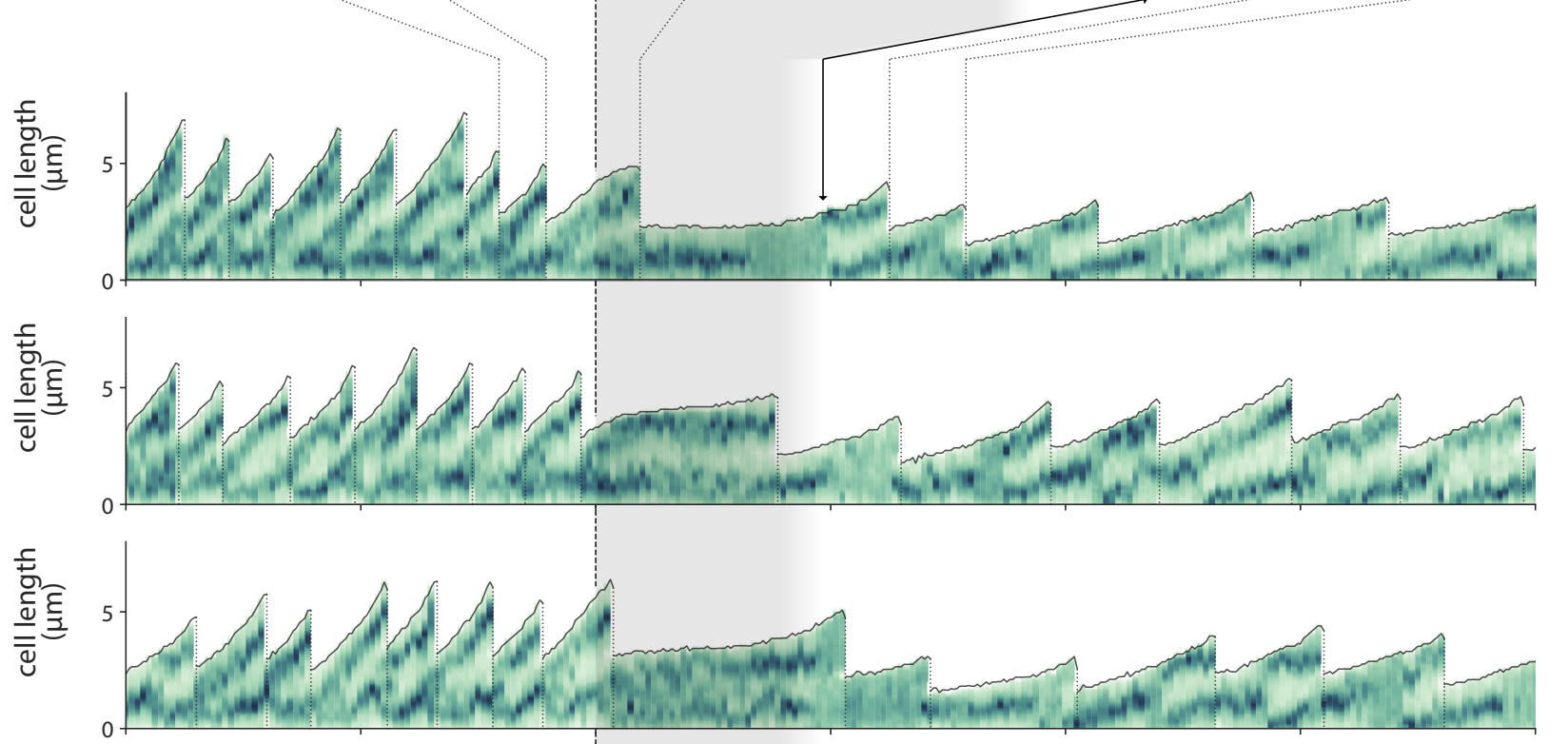

\section{B Population average}

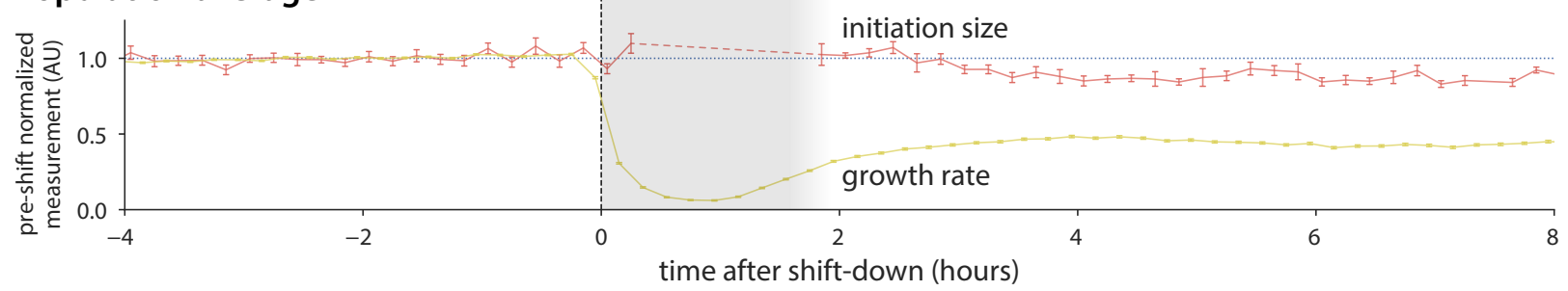

Figure 5: Initiation size is invariant in B. subtilis during shift-down. $\quad$ (A) Behavior of single cells undergoing shift-down from succinate rich to succinate minimal at time zero. Upon shift-down, cells pause growth and initiation for 1-2 hours. Media shift is achieved via a Y-valve upstream of the mother machine inlet. Top: Fluorescent images of cell lineage during shift-down. Bottom: Representative traces of 3 lineages. Representation is as in Figure 3, with the density of the vertical green bars representing the intensity of the DnaN-mGFPmut2 signal along the long-axis of the cell. (B) Population average behavior during shift-down. Growth rate is the instantaneous elongation rate (6 minute time step). Initiation size per ori is plotted against the initiation time. Each measurement is normalized by their respective mean in the 4 hours before shift-down. Lines connect the 12 minute binned mean, and error bars are the standard error of the mean. Minimum bin size is 5. Dashed line in average initiation size signifies gap in initiation events after shift-down. $\mathrm{n}=3,160$ cells (752 with initiation size). Entire time course showing shift-up and shift-down is available in Extended Figure 5-1.

shifting cells from minimal media $(\tau=65$ min) to rich conditions $(\tau=30 \mathrm{~min})$ and back again (Extended Figure 5-1). By using the mother machine, we could add and remove nutrients immediately while measuring the cell cycle and all other physiological parameters (Materials and methods).

The most drastic results occurred upon shift-down (Figure 5). When nutrient supplements were removed, growth immediately paused. The crash in growth rate caused a drastic increase in generation and cell cycle time for cells which experienced the shift-down. Replicating chromosomes were stalled and division ceased. Strikingly, the growth pause led to an absence of initiation events until after cells restarted elongation and attained the requisite initiation size. Thus individual cells maintained a constant initiation size through the transition. Division also resumed after growth recom- menced, but at a smaller size commensurate with the postshift-down growth rate. A constant $\mathrm{C}+\mathrm{D}$ period is not maintained during this time (Extended Figure 5-1).

The decoupling of initiation and division supports the idea that they are controlled by independent threshold mechanisms ${ }^{7}$. That is, the cell builds up a pool of dedicated molecules for each task to a certain level ${ }^{7,12,35-37}$. For initiation, this threshold and the accumulation rate is conserved across growth conditions. For division, the threshold or the accumulation rate is set by the growth condition ${ }^{38}$. In the generation after shift down, cells grow much more slowly and therefore accumulate threshold molecules at a similarly depressed rate. As a result, both initiation and division are delayed. For division, active degradation or antagonization of FtsZ could further hinder the triggering of constriction ${ }^{39,40}$. 


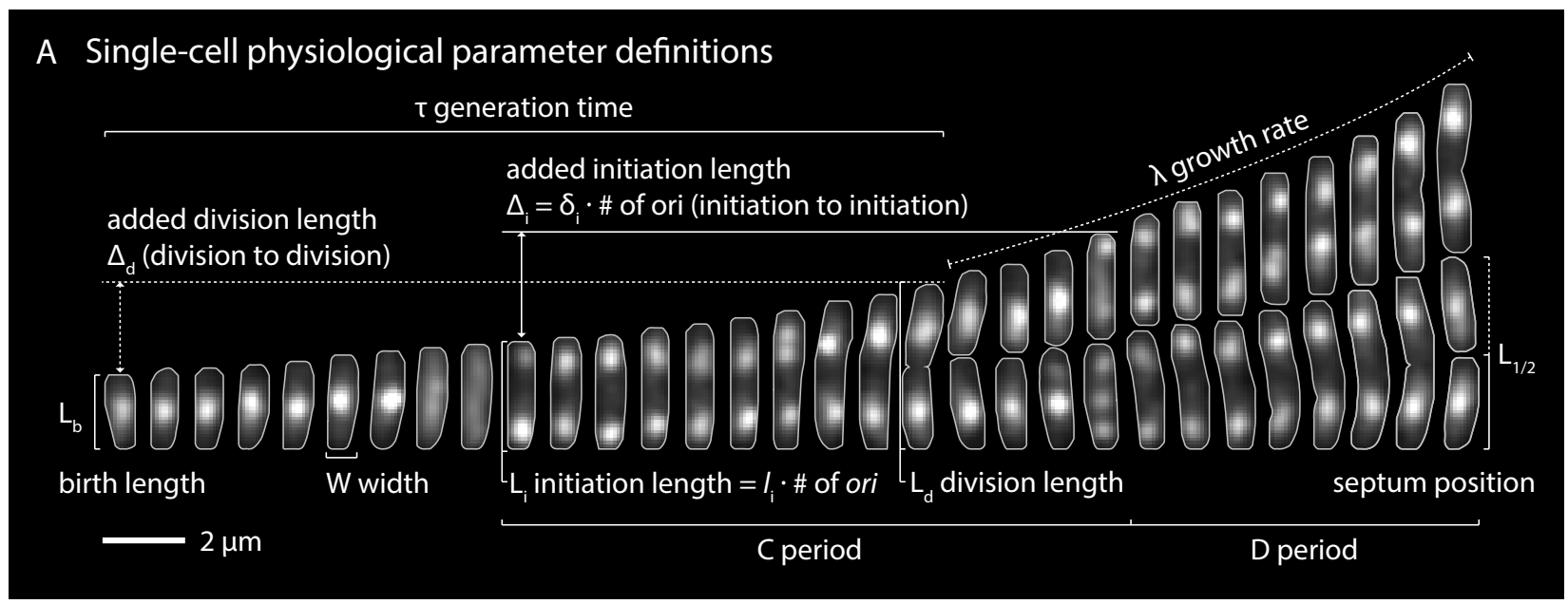

B B. subtilis physiological parameter distributions

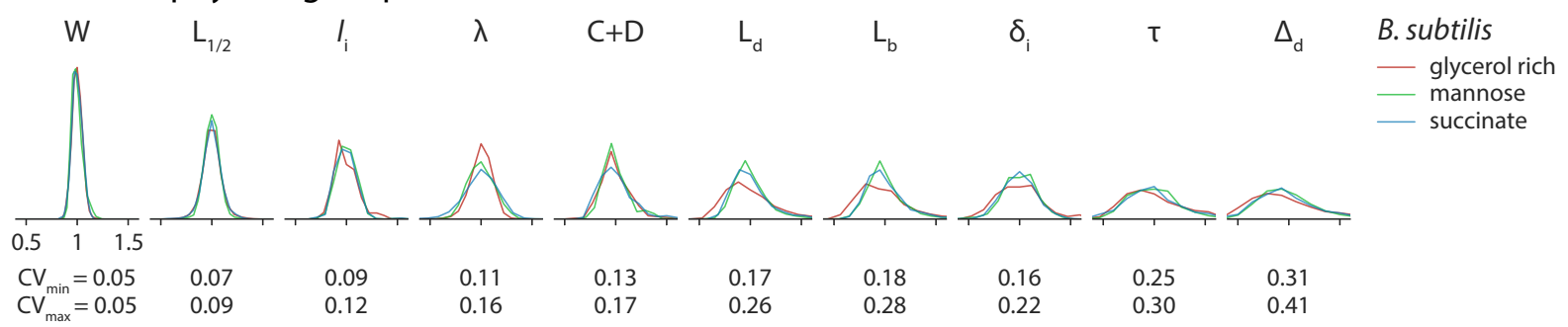

C E. coli physiological parameter distributions

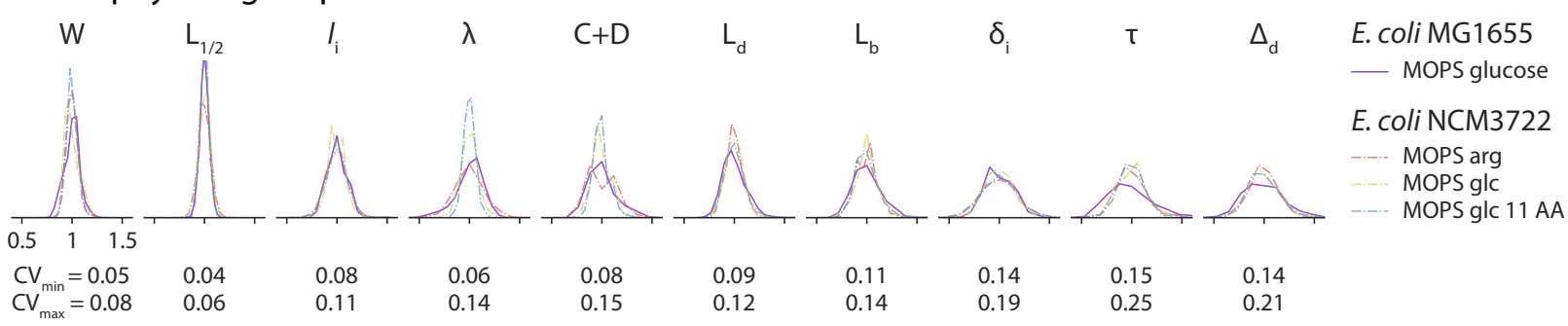

Figure 6: B. subtilis and $\boldsymbol{E}$. coli share the same hierarchy of physiological parameters. $\quad$ (A) Single-cell physiological parameter definitions as determined from time-lapse images. Cells are B. subtilis growing in mannose $(\tau=38$ minutes). Fluorescent signal is DnaN-mGFPmut 2 and grey outlines are from the segmented phase contrast image. Picture interval is 3 minutes. (B) B. subtilis parameter distributions are shown in order of ascending coefficient of variation (CV). Parameters are normalized by their mean. The range of CVs for each parameter is shown below the distributions. Note that length based parameters are shown here; their volume equivalents have slightly higher CVs due to variability in width. (C) Distribution of the same measurements in E. coli display the same CV hierarchy. Data from E. coli NCM3722 grown in MOPS arginine (arg), glucose (glc) and glucose +11 amino acids (glc 11 AA) are from previously published work ${ }^{7}$.

E. coli and $B$. subtilis change cell shape differently under different growth conditions but maintain a constant initiation size

One of the major differences between E. coli and B. subtilis is their shape under different nutrient conditions. Data from our lab and others have shown that the aspect ratio of $E$. coli is nearly constant (approximately 4) under different nutrientimposed growth rates ${ }^{3,41}$. By contrast, the average width of B. subtilis remains relatively constant (Extended Figure 21) ${ }^{9,42}$.

Nevertheless, for initiation control in B. subtilis, we find that volume per ori is more conserved than the length per ori at initiation. While we find length to be a good proxy for initiation size under nutrient limitation, our data show that chloramphenicol treatment decreases cell width in B. subtilis.
Thus, when comparing across all growth conditions, only the initiation volume is constant (Extended Figure 4-1B-D).

\section{B. subtilis is both a division adder and an initi- ation adder}

As previously reported, B. subtilis achieves size homeostasis by following the adder principle ${ }^{6}$. We recently showed that $B$. subtilis, along with $E$. coli, are also initiation adders; the size added per ori between successive initiation events is constant with respect to initiation size ${ }^{7}$. We further tested those results here under additional growth conditions and translational inhibition (Extended Figure 4-2). We find that, for division, our data is best described by the adder principle. However, we note that when going from faster to slower growth condition, the slope becomes slightly negative. This 


\begin{tabular}{|c|l|l|c|c|}
\hline Shared? & $\begin{array}{l}\text { Physiological } \\
\text { principle }\end{array}$ & \multicolumn{1}{|c|}{ B. subtilis } \\
\hline Shared & $\begin{array}{l}\text { Invariant } \\
\text { initiation size }\end{array}$ & $\begin{array}{l}\text { Initiation size is constant in both } \\
\text { nutrient limitiation and antibiot- } \\
\text { ic inhibition conditions. }\end{array}$ & $\begin{array}{l}\text { Initiation and } \\
\text { division size } \\
\text { homeostasis }\end{array}$ & $\begin{array}{l}\text { Initiation and division size } \\
\text { homeostasis is achieved via } \\
\text { the adder principle. }\end{array}$ \\
\hline Shared & $\begin{array}{l}\text { Parameter } \\
\text { hierarchy }\end{array}$ & $\begin{array}{l}\text { CV of physiological parameters } \\
\text { retains same order. CVs are } \\
\text { independent of growth condition. }\end{array}$ \\
\hline $\begin{array}{l}\text { Partially } \\
\text { shared }\end{array}$ & $\begin{array}{l}\text { Cell size } \\
\text { and shape } \\
\text { behavior }\end{array}$ & $\begin{array}{l}\text { Cell size increases with growth rate due to } \\
\text { extension in length. Constant width. }\end{array}$ & $\begin{array}{l}\text { Cell size increases exponentially with } \\
\text { growth rate. Proportional increase in } \\
\text { length and width. }\end{array}$ \\
\hline
\end{tabular}

Figure 7: B. subtilis and E. coli comparative summary.

may be due to active degradation or inhibition of FtsZ assem-

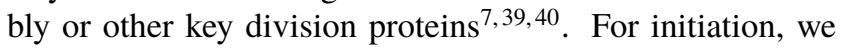
again find that our data is best described by the adder principle. Importantly, the added size between initiation and added size between division are uncorrelated (Extended Figure 63), consistent with initiation and division being controlled by separate threshold mechanisms ${ }^{7}$. While both processes are tied to global biosynthesis, this indicates minimal crosstalk between the two in steady-state conditions.

\section{B. subtilis and $E$. coli share the same hierarchy of physiological parameters}

The coefficient of variation (CV) of a distribution of a physiological parameter is often interpreted as the tightness of the underlying biological control ${ }^{43}$. We extended previous analysis to include the cell cycle related parameters $C$ period, D period, initiation size, and added initiation size for both B. subtilis and E. coli. We found that both evolutionarily distant organisms share the same order of their physiological parameters in terms of CV (Figure 6). Width, septum position, initiation size, and growth rate are the tightest of the parameters. D period is significantly more variable than $\mathrm{C}$ period, and they are inversely correlated. In fact, the $\mathrm{CV}$ of a particular physiological parameter is extremely similar across growth conditions, species, and strains (Extended Figure 6-1).

Ultimately, the $\mathrm{CV}$ of the physiological parameters is the manifestation of molecular regulatory mechanisms. Classically, B. subtilis and E. coli provide excellent examples of both homologous and non-homologous versions of such mechanisms. For example, major protein players controlling replication and division, such as DnaA and FtsZ, are conserved in these and most other prokaryotes ${ }^{44,45}$. However, the regulation of those molecules in B. subtilis and E. coli is unique $^{46-48}$. More generally, the two species often use unrelated mechanisms to achieve the same regulatory goal ${ }^{48,49}$. Because of their phylogenetic distance, the uncanny agreement between the CVs of their physiological parameters suggests an evolutionary ancient control framework shared by these organisms.

\section{Summary and Outlook}

We have shown that B. subtilis and E. coli, despite their historical separation across the Gram stain divide, share extremely similar fundamental physiological behavior (Figure 7). Under a wide range of nutrient and growth inhibition conditions, both species base their chromosome replication in a constant initiation size. Impressively, this constant initiation size is imposed even during dynamic growth transitions. This is consistent with a threshold mechanism and constant production of cell cycle initiator proteins for initiation and division timing control, thus maintaining size homeostasis with the adder principle ${ }^{7}$.

As with E. coli, DnaA and FtsZ are among the key proteins responsible for the initiation and division threshold mechanisms in $B$. subtilis, respectively ${ }^{7,13,50}$. The view that global biosynthesis fundamentally controls their production, and thus the replication and division rate, is still compatible with the idea that additional levels of regulation modulate or coordinate their activity in certain situations ${ }^{46,51}$. It is unclear whether these additional mechanisms have evolved to increase replication and division fidelity during steady-state or 
bioRxiv preprint doi: https://doi.org/10.1101/726596; this version posted August 6,2019 . The copyright holder for this preprint (which was not certified by peer review) is the author/funder. All rights reserved. No reuse allowed without permission.

are more important in dynamic environments. More singlecell shift experiments with mutant or even minimal genome cells will help reveal the importance of redundant regulatory systems.

These deep similarities between B. subtilis and E. coli speak to a conserved control framework which both species use to coordinate growth, DNA replication, and division. In doing so, they ensure life's essential demand of physiological homeostasis. In the end, it is unclear if this framework is the result of parallel or convergent evolution. In order to better address this question, more quality single-cell data is needed from diverse prokaryotes. In either case, the existence of a shared control framework underscores its efficacy, providing an intriguing avenue for the development of synthetic organisms.

\section{References}

[1] S. Jun, F. Si, R. Pugatch, \& M. Scott, "Fundamental Principles in Bacterial Physiology - History, Recent progress, and the Future with Focus on Cell Size Control: A Review," Reports on Progress in Physics, 2017.

[2] M. Schaechter, O. Maaløe, \& N. O. Kjeldgaard, "Dependency on medium and temperature of cell size and chemical composition during balanced grown of Salmonella typhimurium.," Journal of general microbiology, 19, 592-606, dec 1958.

[3] F. Si, D. Li, S. E. Cox, J. T. Sauls, O. Azizi, C. Sou, A. B. Schwartz, M. J. Erickstad, Y. Jun, X. Li, \& S. Jun, "Invariance of Initiation Mass and Predictability of Cell Size in Escherichia coli," Current Biology, 27, 1278-1287, may 2017.

[4] I. Lozada-Chávez, S. C. Janga, \& J. Collado-Vides, "Bacterial regulatory networks are extremely flexible in evolution," Nucleic Acids Research, 34, 3434-3445, 2006.

[5] M. Campos, I. V. Surovtsev, S. Kato, A. Paintdakhi, B. Beltran, S. E. Ebmeier, \& C. Jacobs-Wagner, "A constant size extension drives bacterial cell size homeostasis.," Cell, 159, 1433-46, dec 2014.

[6] S. Taheri-Araghi, S. Bradde, J. T. Sauls, N. S. Hill, P. A. Levin, J. Paulsson, M. Vergassola, \& S. Jun, "Cell-size control and homeostasis in bacteria.," Current biology, 25, 385-91, feb 2015.

[7] F. Si, G. Le Treut, J. T. Sauls, S. Vadia, P. A. Levin, \& S. Jun, "Mechanistic Origin of Cell-Size Control and Homeostasis in Bacteria.," Current Biology, p. 478818, may 2019.

[8] W. D. Donachie, "Relationship between Cell Size and Time of Initiation of DNA Replication," Nature, 219, 1077-1079, sep 1968.

[9] M. E. Sharpe, P. M. Hauser, R. G. Sharpe, \& J. Errington, "Bacillus subtilis cell cycle as studied by fluorescence microscopy: Constancy of cell length at initiation of DNA replication and evidence for active nucleoid partitioning," Journal of Bacteriology, 180, 547-555, 1998.

[10] N. S. Hill, R. Kadoya, D. K. Chattoraj, \& P. A. Levin, "Cell size and the initiation of DNA replication in bacteria," PLoS Genetics, 8, p. e1002549, jan 2012.

[11] M. Wallden, D. Fange, E. Gregorsson Lundius, Ö. Baltekin, \& J. Elf, "The synchronization of replication and division cycles in individual E. coli cells (in press)," Cell, 729-739, 2016.

[12] C. E. Helmstetter, S. Cooper, O. Pierucci, \& E. Revelas, "On Bacterial Life Sequence," Cold Spring Harbor Symposia on Quantitative Biology, 33, 809-\&, 1968.

[13] A. Løbner-Olesen, K. Skarstad, F. G. Hansen, K. von Meyenburg, \& E. Boye, "The DnaA protein determines the initiation mass of Escherichia coli K-12.," Cell, 57, 881-889, 1989.

[14] R. J. Paulton, "Nuclear and cell division in filamentous bacteria.," Nature New Biology, 231, 271-274, jun 1971.

[15] T. M. Norman, N. D. Lord, J. Paulsson, \& R. Losick, "Stochastic Switching of Cell Fate in Microbes," Annual Review of Microbiology, 69, p. 150902154308007, 2015.

[16] R. J. Paulton, "Analysis of the multiseptate potential of Bacillus subtilis.," Journal of Bacteriology, 104, 762-767, 1970.

[17] N. Nanninga, L. J. H. Koppes, \& F. C. de Vries-Tijssen, "The cell cycle of Bacillus subtilis as studied by electron microscopy," Archives of Microbiology, 123, 173-181, 1979.

[18] R. Chen, S. B. Guttenplan, K. M. Blair, \& D. B. Kearns, "Role of the $\sigma \mathrm{D}$-dependent autolysins in Bacillus subtilis population heterogeneity," Journal of Bacteriology, 191, 5775-5784, 2009.

[19] P. Wang, L. Robert, J. Pelletier, W. L. Dang, F. Taddei, A. Wright, \& S. Jun, "Robust growth of Escherichia coli.," Current biology, 20, 1099-103, jun 2010.

[20] R. B. Weart, A. H. Lee, A. C. Chien, D. P. Haeusser, N. S. Hill, \& P. A. Levin, "A Metabolic Sensor Governing Cell Size in Bacteria," Cell, 130, 335-347, 2007.

[21] M. Basan, M. Zhu, X. Dai, M. Warren, D. Sévin, Y.-p. Wang, \& T. Hwa, "Inflating bacterial cells by increased protein synthesis.," Molecular systems biology, 11, p. 836, 2015. 
bioRxiv preprint doi: https://doi.org/10.1101/726596; this version posted August 6, 2019. The copyright holder for this preprint (which was not certified by peer review) is the author/funder. All rights reserved. No reuse allowed without permission.

[22] H. Yoshikawa \& N. Sueoka, "Sequential replication of Bacillus subtilis chromosome. I. Comparison of marker frequencies in exponential and stationary growth phases.," Proceedings of the National Academy of Sciences of the United States of America, 49, 559-66, apr 1963.

[23] L. A. Simmons, B. W. Davies, A. D. Grossman, \& G. C. Walker, "Beta clamp directs localization of mismatch repair in Bacillus subtilis.," Molecular cell, 29, 291-301, feb 2008.

[24] S. M. Mangiameli, B. T. Veit, H. Merrikh, \& P. A. Wiggins, "The Replisomes Remain Spatially Proximal throughout the Cell Cycle in Bacteria," PLoS Genetics, 13, 1-17, 2017.

[25] X. Wang, P. Montero Llopis, \& D. Z. Rudner, "Bacillus subtilis chromosome organization oscillates between two distinct patterns.," Proceedings of the National Academy of Sciences of the United States of America, 111, jul 2014.

[26] A. I. Goranov, A. M. Breier, H. Merrikh, \& A. D. Grossman, "Yaba of bacillus subtilis controls DnaA-mediated replication initiation but not the transcriptional response to replication stress," Molecular Microbiology, 74, 454-466, 2009.

[27] H. Merrikh \& A. D. Grossman, "Control of the replication initiator DnaA by an anti-cooperativity factor," Molecular Microbiology, 82, 434-446, oct 2011.

[28] E. Cho, N. Ogasawara, \& S. Ishikawa, "The functional analysis of YabA, which interacts with DnaA and regulates initiation of chromosome replication in Bacillus subtils," Genes \& Genetic Systems, 83, 111-125, 2008.

[29] S. Cooper \& C. E. Helmstetter, "Chromosome replication and the division cycle of Escherichia coli B/r.," Journal of molecular biology, 31, 519-40, feb 1968.

[30] M. Holmes, M. Rickert, \& O. Pierucci, "Cell division of cycle of Bacillus subtilis: evidence of variability in period D.," Journal of bacteriology, 142, 254-61, apr 1980.

[31] Y. Ogura, Y. Imai, N. Ogasawara, \& S. Moriya, "Autoregulation of the dnaA-dnaN operon and effects of DnaA protein levels on replication initiation in Bacillus subtilis," Journal of Bacteriology, 183, 3833-3841, 2001.

[32] N. O. Kjeldgaard, O. Maaløe, \& M. Schaechter, "The transition between different physiological states during balanced growth of Salmonella typhimurium.," Journal of general microbiology, 19, 607-16, dec 1958.

[33] F. C. Neidhardt \& B. Magasanik, "Studies on the role of ribonucleic acid in the growth of bacteria," Biochimica et Biophysica Acta, 42, 99-116, jan 1960.

[34] S. Cooper, "Cell division and DNA replication following a shift to a richer medium," Journal of Molecular Biology, 43, 1-11, jul 1969.

[35] W. D. Donachie, D. T. M. Martin, \& K. J. Begg, "Independence of cell division and DNA replication in Bacillus subtilis," Nature New Biology, 231, 274-276, 1971.

[36] R. M. Teather, J. F. Collins, \& W. D. Donachie, "Quantal behavior of a diffusible factor which initiates septum formation at potential division sites in Escherichia coli," Journal of Bacteriology, 118, 407-413, 1974.

[37] A. C. Chien, N. S. Hill, \& P. A. Levin, "Cell size control in bacteria," Current Biology, 22, R340-R349, 2012.

[38] R. B. Weart \& P. A. Levin, "Growth rate dependent regulation of medial FtsZ ring formation in Bacillus subtilis," Journal of Bacteriology, 185, p. 2826, 2003.

[39] K. Sekar, R. Rusconi, J. T. Sauls, T. Fuhrer, E. Noor, J. Nguyen, V. I. Fernandez, M. F. Buffing, M. Berney, S. Jun, R. Stocker, \& U. Sauer, "Synthesis and degradation of FtsZ quantitatively predict the first cell division in starved bacteria.," Molecular systems biology, 14, p. e8623, nov 2018.

[40] R. B. Weart, S. Nakano, B. E. Lane, P. Zuber, \& P. A. Levin, "The ClpX chaperone modulates assembly of the tubulin-like protein FtsZ," Molecular Microbiology, 57, 238-249, 2005.

[41] A. Zaritsky, "On dimensional determination of rod-shaped bacteria," Journal of Theoretical Biology, 54, 243-248, 1975.
[42] M. F. Dion, M. Kapoor, Y. Sun, S. Wilson, J. Ryan, A. Vigouroux, S. van Teeffelen, R. Oldenbourg, \& E. C. Garner, "Bacillus subtilis cell diameter is determined by the opposing actions of two distinct cell wall synthetic systems," Nature Microbiology, 2019.

[43] A. L. Koch \& M. Schaechter, "A model for statistics of the cell division process.," Journal of general microbiology, 29, 435-54, nov 1962.

[44] J. Löwe \& L. A. Amos, "Evolution of cytomotive filaments: The cytoskeleton from prokaryotes to eukaryotes," International Journal of Biochemistry and Cell Biology, 41, 323-329, 2009.

[45] T. Katayama, S. Ozaki, K. Keyamura, \& K. Fujimitsu, "Regulation of the replication cycle: conserved and diverse regulatory systems for DnaA and oriC.," Nature reviews. Microbiology, 8, 163-70, mar 2010.

[46] I. V. Hajduk, C. D. Rodrigues, \& E. J. Harry, "Connecting the dots of the bacterial cell cycle: Coordinating chromosome replication and segregation with cell division," Seminars in Cell and Developmental Biology, 53, 2-9, 2016.

[47] J. Errington \& L. J. Wu, "Cell Cycle Machinery in Bacillus subtilis," in Prokaryotic Cytoskeletons, vol. 84, 67-101, 2017.

[48] K. H. Jameson \& A. J. Wilkinson, "Control of initiation of DNA replication in Bacillus subtilis and Escherichia coli," Genes, 8, 2017.

[49] N. S. Hill, P. J. Buske, Y. Shi, \& P. A. Levin, "A moonlighting enzyme links Escherichia coli cell size with central metabolism.," PLoS genetics, 9, p. e1003663, jan 2013.

[50] E. Bi \& J. Lutkenhaus, "FtsZ regulates frequency of cell division in Escherichia coli," Journal of Bacteriology, 172, 2765-2768, 1990.

[51] J. Männik \& M. W. Bailey, "Spatial coordination between chromosomes and cell division proteins in Escherichia coli," Frontiers in Microbiology, 6, 1-8, 2015.

[52] M. A. Konkol, K. M. Blair, \& D. B. Kearns, "Plasmid-encoded comi inhibits competence in the ancestral 3610 strain of Bacillus subtilis," Journal of Bacteriology, 195, 4085-4093, 2013.

[53] P. R. Bennallack, S. R. Burt, M. J. Heder, R. A. Robison, \& J. S. Griffitts, "Characterization of a novel plasmid-borne thiopeptide gene cluster in Staphylococcus epidermidis strain 115," Journal of Bacteriology, 196, 4344-4350, 2014.

[54] R. Reyes-Lamothe, D. J. Sherratt, \& M. C. Leake, "Stoichiometry and architecture of active DNA replication machinery in Escherichia coli.," Science, 328, 498-501, apr 2010.

[55] S. Taheri-Araghi, S. D. Brown, J. T. Sauls, D. B. Mclntosh, \& S. Jun, "Single-Cell Physiology," Annual review of biophysics, 44, 123-42, 2015.

[56] P. A. Levin, "6 Light microscopy techniques for bacterial cell biology," in Methods in Microbiology 31: Molecular Cellular Microbiology, 115-132, 2002.

[57] O. Ronneberger, P. Fischer, \& T. Brox, "U-Net: Convolutional Networks for Biomedical Image Segmentation," in Medical Image Computing and Computer-Assisted Intervention-MICCAI 2015, vol. 9351, 234-241, 2015.

[58] T. R. Beattie, N. Kapadia, E. Nicolas, S. Uphoff, A. J. Wollman, M. C. Leake, \& R. Reyes-Lamothe, "Frequent exchange of the DNA polymerase during bacterial chromosome replication," eLife, 6, 1-20, 2017.

[59] S. M. Mangiameli, C. N. Merrikh, P. A. Wiggins, \& H. Merrikh, "Transcription leads to pervasive replisome instability in bacteria," eLife, 6, 1-27, 2017.

Acknowledgements This work was supported by the Paul G. Allen Family Foundation, Pew Charitable Trust, NSF CAREER grant MCB-1253843, and NIH grant R01 GM118565-01 (to S.J.).

Author Information The authors declare no competing financial interests. Correspondence and requests for materials should be addressed to S.J. suckjoon.jun@gmail.com 
bioRxiv preprint doi: https://doi.org/10.1101/726596; this version posted August 6, 2019. The copyright holder for this preprint (which was not certified by peer review) is the author/funder. All rights reserved. No reuse allowed without permission.

\section{Materials and methods}

Strains. We used B. subtilis strains in the 3610 background with mutations to confer non-motility and reduce biofilm formation ${ }^{6}$. The background strain contained $\operatorname{comI}(\mathrm{Q} 12 \mathrm{~L})$ to confer competence ${ }^{52}$. We used an inducible lyt $F$ construct to prevent chaining ${ }^{18}$. For mother machine experiments in which replisomes were tracked, we used dnaNmGFPmut $2^{23,24}$. Strain construction was performed using single crossover plasmid recombination or double crossover recombination from genomic $\mathrm{DNA}^{53}$.

For $E$. coli, we used a K-12 MG1655 strain containing a functional dnaN-YPet construct ${ }^{54}$. Strain genotypes for both species are provided in Table 2.

Growth media and experimental conditions. For B. subtilis, we used $\mathrm{S}_{50}$ medium with different carbon sources and supplements. Importantly, we included additional iron(III) chloride and trisodium citrate. The latter acts as a siderophore for B. subtilis, and without it our strain cannot grow in the mother machine ${ }^{55}$. To make rich conditions, we added $2 \mathrm{mg} / \mathrm{mL}$ casamino acids and $0.04 \mathrm{mg} / \mathrm{mL}$ tryptophan. For E. coli, we used MOPS glucose medium. Turbidostat and mother machine experiments used the same media with the following addition: bovine serum albumin was added at 0.5 $\mathrm{mg} / \mathrm{mL}$ during mother machine experiments in order to reduce cell adherence to surfaces inside the device. Tables 3 and 4 provide detailed information on media composition.

For both turbidostat and mother machine experiments, chloramphenicol was added at concentrations between 1and $4.2 \mu \mathrm{M}$ during translational inhibition experiments. All experiments were performed at $37^{\circ} \mathrm{C}$ in a climate controlled environmental room which housed the multiplex turbidostat and all optical components (Darwin Chambers Company, MO). Tables 5 and 6 enumerate experimental conditions and sample size for turbidostat and mother machine experiments, respectively.

Microscopy configuration. We performed phase contrast and fluorescent imaging on a Nikon Ti-E inverted microscope with Perfect Focus (PFS) and an LED transmission light source, controlled by Nikon Elements. For turbidostat experiments we used a PFS 2, CoolLED pE-100, 60X 1.4 NA Ph3 oil immersion objective (Nikon CFI Plan Apo DM Lambda 60X Oil), and Andor Technology Neo sCMOS camera. For fixed cell phase contrast imaging, we used exposure times between $50-100 \mathrm{~ms}$ and $100 \%$ transmission power.

For mother machine experiments, we used a PFS 3, Sutter Instruments TLED, 100X 1.45 NA Ph3 oil immersion objective (Nikon CFI Plan Apo DM Lambda 100X Oil), Photometrics Prime 95B sCMOS camera, and Coherent Obis laser 488LX for epifluorescent illumination. For laser epifluorescent illumination, we inserted a rotating diffuser in the optical train to reduce speckle. We also reduced the camera sensor region of interest to flatten the fluorescent illumination profile. We used a Chroma filter cube with dichroic mirror ZT488rdc and emission filter ET252/50m. For live cell phase contrast imaging, we used a $30 \mathrm{~ms}$ exposure time at $100 \%$ transmission power at an interval of 1.5 minutes. For fluorescent imaging, we used a 25 or $50 \mathrm{~ms}$ exposure time at $25 \%$ power at an interval of 3 minutes. This weak illumination minimized physiological effects due to photo- toxicity on the cell and allowed for steady-state behavior over many hours.

Turbidostat cell preparation and sample collection. We grew all pre-cultures at $32^{\circ} \mathrm{C}$ or $37^{\circ} \mathrm{C}$ in a water bath shaker at $260 \mathrm{rpm}$. Seed cultures were inoculated into 1-3 mL LB medium from a single colony from an agar plate, streaked no more than 2 days before use. Cells were grown for several hours then diluted 1,000-fold into the target media without antibiotics and grown until $\mathrm{OD}_{600} 0.1$. If multiple back dilution rounds were needed to control experimental timing, they were done such that cells did not enter stationary phase. The culture was then inoculated into each turbidostat vial with or without antibiotics to the target $\mathrm{OD}_{600} 0.05$. Cultures grew for a minimum of 14 doublings to ensure steady-state conditions upon sample collection. For some conditions, cells adhered to the glass culture vial, evidence of residual biofilm activity we observed as changes in growth rate over the time course. In these cases, the sample was transferred to a clean glass vial at the end of the experiment for at least 1 additional doubling from which the growth rate was determined.

We collected samples for cell size and cell cycle measurements at $\mathrm{OD}_{600} 0.2$. Approximately $20 \mathrm{~mL}$ of cell culture was immediately put on ice to arrest growth. The culture was then split and pelleted, frozen, or fixed according to the subsequent measurement protocol. Our turbidostat design and function has been previously described ${ }^{3}$.

Turbidostat growth rate measurement. The turbidostat maintained cells growing exponentially between $\mathrm{OD}_{600} 0.05$ and 0.2. In effect, it was run as a batch growth repeater, diluting the culture to $\mathrm{OD}_{600} 0.05$ when it reached $\mathrm{OD}_{600}$ 0.2. An exponential line was fit to the growth periods between consecutive dilution events. From the exponential line $I=I_{0} \cdot 2^{t / \tau}$, the growth rate was determined as $\lambda=\ln 2 / \tau$, where $\tau$ is the doubling time. The turbidostat spectrometers were blanked with the appropriate medium before each experiment.

Turbidostat cell size measurement. We fixed cells with a glutaraldehyde and paraformaldehyde mixture and imaged within $24 \mathrm{hr}$ as previously reported ${ }^{56}$, except for the following modifications: $2 \mu 125 \%$ glutaraldehyde was added to $1 \mathrm{ml}$ $16 \%$ paraformaldehyde and cells were resuspended in $300 \mu \mathrm{l}$ GTE (50mM Glucose 25mM Tris 8.0 10mM EDTA 8.0) per sample after PBS washes.

Before imaging, we adjusted cells to an appropriate cell density as needed. Cells were pipetted onto a $2 \%$ agarose pad and briefly dried. The agarose pad was then flipped onto a Willco dish (WillCo Wells, Netherlands) and covered with a glass coverslip to reduce evaporation during imaging. Each experiment consisted of 80-200 images. Sample sizes are presented in Table 5.

We performed fixed cell image analysis with a custom Python script using the OpenCV library. First, we detected contours using an active snakes edge detection algorithm. We then filtered for cell contours using a priori knowledge of cell size and shape, and manually checked for correctly segmented cells. Width and length were calculated from the long and short axis of the cell segments using a simple threshold on the raw phase contrast images. All segmented cells where the width and length fell within 3 standard devia- 
tions of the mean for that measurement were kept for further analysis. To calculate cell volume, we assumed the cell was a cylinder with hemispherical ends.

Turbidostat $\mathbf{C}$ period measurement using qPCR. We estimated $\mathrm{C}$ period using qPCR and marker frequency analysis. Genomic DNA was prepared from each turbidostat sample using a standard phenol chloroform extraction. We amplified genomic DNA using PowerUp SYBR Green Master Mix (Thermo Fisher Scientific). We used primer pairs targeting chromosomal loci and calculated the $\mathrm{C}$ period using the ratio of relative loci copy numbers as discussed previously ${ }^{3}$. Primers are listed in Table 6.

Mother machine cell preparation and image acquisition. We prepared cultures for mother machine experiments the same as for turbidostat experiments except for the following difference: for translational inhibition experiments, the culture was diluted into the target media with appropriate antibiotics and allowed to grow for several generations before loading into the device.

We performed mother machine experiments as previously described $^{6,7}$. We used a custom centrifuge to load cells into the growth channels of the mother machine. The time required to remove cells from the water bath shaker, load them into the growth channels, and infuse fresh $37^{\circ} \mathrm{C}$ media was between 15 and 30 minutes. We then imaged cells for many hours under constant media infusion via a syringe pump (Harvard Apparatus, MA).

For nutrient shift experiments, two syringe pumps were used in conjunction with a manual Y-valve near the device inlet. Cells experienced the change in nutrients in a time interval shorter than the imaging interval ${ }^{39}$.

Mother machine image processing. Mother machine images were processed with custom Python software. The pipeline takes raw images and produces objects which represent a cell and contains all measured parameters. Briefly, the software aligns and crops images into single channels, segments cells, and links segments in time to construct cell lives and lineages. From the constructed cells we extracted physical parameters in space and time such as size and growth rate. The software has been previously described ${ }^{7}$ with the following modification: segmentation was accomplished with a convolutional neural network implemented with TensorFlow using manually annotated training data ${ }^{57}$.

After segmentation and lineage creation, the resulting cells were filtered for those with measured parameters (septum position, elongation rate, generation time, and birth, division and added length) within 4 standard deviations of their respective population means. We only considered cells in the time interval for which measured parameters and the fluorescent signal were in steady-state. This was normally 3-4 hours after imaging began until imaging ceased. For the growth condition glycerol rich with $3.5 \mu \mathrm{M}$ chloramphenicol, we excluded cells which divided at the quarter positions, which were less than $5 \%$ of all cells. For all conditions, we further selected a subset of cells which could be followed for at least 4-6 consecutive generations. The later filtering step did not affect the parameter distributions, but ensured cell cycle determination was possible in light of the presence of overlapping cell cycles. We only considered mother cells during analysis, but note that other cells along the channel had identical elongation rates.

Single-cell cell cycle analysis. As described in the main text we used a functional fluorescent DnaN-mGFPmut2 fusion protein. The construct was integrated at the chromosomal locus and expressed under the native promoter. This gene product is the $\beta$-clamp subunit of DNA polymerase III, which is present at high stoichiometry in active replisomes ${ }^{54}$.

Cell cycle analysis is as described previously ${ }^{7}$. Processed fluorescent images were used to determine the cell cycle parameters manually. We first identified replisome foci in the processed fluorescent images using a Laplacian of Gaussian blob detection method. We then constructed cell traces by plotting cell length versus time, with both the fluorescent signal and foci position projected against the long axis of the cell as demonstrated in Figure 3. Using an interactive program, we determined the start and end of replication visually based on the position and number of detected foci. For the fastest two growth conditions, glycerol rich with 0 and $1 \mu \mathrm{M}$ chloramphenicol, termination time and thus $\mathrm{C}$ and $\mathrm{D}$ period were not determined separately.

Ensemble cell cycle analysis. In the ensemble method, we aligned cells by size and plotted the ensemble replication state. Based on ours and published measurements, we chose alignment by size as opposed to cell age ${ }^{11}$. To create the ensemble, we find the average number of foci as a function of cell size across all cells. For the slow growing case, the number of foci is 1 at small lengths until a transition period, at which it rises to and plateaus at 2 . We take the initiation length to be the length at which the foci count rate of change is the highest, using a differentiation step of $0.2 \mu \mathrm{m}$. By inferring the average number of overlapping cell cycles $n_{\mathrm{oc}}$ from the traces, we can calculate $\mathrm{C}+\mathrm{D}$ to be $\mathrm{C}+\mathrm{D}=\left(n_{\mathrm{oc}}+\log _{2}\left(S_{\mathrm{d}} / S_{\mathrm{i}}\right)\right) \cdot \tau$.

Data and code availability Data and code involved in this study are available upon request. 


\section{Tables}

\begin{tabular}{|l|l|l|}
\hline B. subtilis strains & Genotype & Notes \\
\hline BS15 & $\begin{array}{l}3610 \text { comI(Q12L) hag::MLS(R)::MLS(S) } \\
\text { amyE::[Phyperspank-lytF spcR] epsH::tet }\end{array}$ & $\begin{array}{l}\text { Gift from Petra Levin; Used for } \\
\text { turbidostat experiments. }\end{array}$ \\
\hline BS45 & $\begin{array}{l}3610 \quad \text { comI(Q12L) motAB::Tn917 } \\
\text { amyE::[Physpank-lytF kan] epsH::tet } \\
\text { dnaN::[dnaN-gfp spec] }\end{array}$ & $\begin{array}{l}\text { This study; Used for microfluidic } \\
\text { and turbidostat experiments. }\end{array}$ \\
\hline E. coli strains & $\begin{array}{l}\text { K-12 MG1655 dnaN::[dnaN-yPet kan] } \\
\text { hupA::[hupA-mRuby2 FRT-cat-FRT] }\end{array}$ & $\begin{array}{l}\text { This study; Used for microfluidic } \\
\text { experiments. }\end{array}$ \\
\hline SJ1724 &
\end{tabular}

Table 1: Strain information. 


\begin{tabular}{|c|c|c|c|c|c|}
\hline Media name & Abbreviation & Carbon source & Nitrogen source & Buffer, salts and metals & Supplement \\
\hline $\mathrm{S}_{50}$ succinate & suc & $1 \%$ succinate & $0.1 \%$ glutamate & $\mathrm{S}_{50}$ salts and metals & - \\
\hline $\mathrm{S} 750$ mannose & man & $1 \%$ mannose & $0.1 \%$ glutamate & S7 50 salts and metals & - \\
\hline S750 glycerol & gly & $1 \%$ glycerol & $0.1 \%$ glutamate & $\mathrm{S}_{50}$ salts and metals & - \\
\hline S750 succinate rich & suct & $1 \%$ succinate & $0.1 \%$ glutamate & S750 salts and metals & $0.2 \mathrm{mg} / \mathrm{ml}$ casamino acids, $0.04 \mathrm{mg} / \mathrm{ml}$ tryptophan \\
\hline $\mathrm{S}_{50}$ mannose rich & man+ & $1 \%$ mannose & $0.1 \%$ glutamate & S7 50 salts and metals & $0.2 \mathrm{mg} / \mathrm{ml}$ casamino acids, $0.04 \mathrm{mg} / \mathrm{ml}$ tryptophan \\
\hline S750 glycerol rich & gly+ & $1 \%$ glycerol & $0.1 \%$ glutamate & S7 50 salts and metals & $0.2 \mathrm{mg} / \mathrm{ml}$ casamino acids, $0.04 \mathrm{mg} / \mathrm{ml}$ tryptophan \\
\hline MOPS glucose & MOPS glc & $0.2 \%$ glucose & $9.5 \mathrm{mM}$ ammonium chloride & MOPS modified buffer & - \\
\hline LB & LB & $0.5 \%$ glucose & - & - & $1 \%$ tryptone, $0.5 \%$ yeast extract, $0.05 \% \mathrm{NaCl}$ \\
\hline
\end{tabular}

Table 2: Growth media. 


\begin{tabular}{|l|l|}
\hline Component & Concentration \\
\hline S7 50 salts and metals & $50 \mathrm{mM}$ \\
\hline MOPS & $1 \mathrm{mM}$ \\
\hline ammonium sulfate & $5 \mathrm{mM}$ \\
\hline potassium phosphate monobasic & $2 \mathrm{mM}$ \\
\hline magnesium chloride & $0.7 \mathrm{mM}$ \\
\hline calcium chloride & $50 \mu \mathrm{M}$ \\
\hline manganese(II) chloride & $1 \mu \mathrm{M}$ \\
\hline zinc chloride & $55 \mu \mathrm{M}$ \\
\hline iron(III) chloride & $1 \mathrm{mM}$ \\
\hline thiamine hydrochloride & $20 \mu \mathrm{M}$ \\
\hline hydrogen chloride & $50 \mu \mathrm{M}$ \\
\hline trisodium citrate & \\
\hline MOPS modified buffer & $40 \mathrm{mM}$ \\
\hline MOPS & $4 \mathrm{mM}$ \\
\hline tricine & $0.1 \mathrm{mM}$ \\
\hline iron(III) sulfate & $0.276 \mathrm{mM}$ \\
\hline sodium sulfate & $0.5 \mu \mathrm{M}$ \\
\hline calcium chloride & $0.525 \mathrm{mM}$ \\
\hline magnesium chloride & $50 \mathrm{mM}$ \\
\hline sodium chloride & $3 \mathrm{nM}$ \\
\hline ammonium molybdate & $0.4 \mu \mathrm{M}$ \\
\hline boric acid & $30 \mathrm{nM}$ \\
\hline cobalt chloride & $10 \mathrm{nM}$ \\
\hline cupric sulfate & $80 \mathrm{nM}$ \\
\hline manganese(II) chloride & $10 \mathrm{nM}$ \\
\hline zinc sulfate & $1.32 \mathrm{mM}$ \\
\hline potassium phosphate monobasic & \\
\hline
\end{tabular}

Table 3: Media components.

\begin{tabular}{|l|l|l|l|l|}
\hline Strain & Growth medium & Perturbation & Replicates & Sample size \\
\hline BS15 & succinate & none & 4 & $6592,8769,74187051$ \\
\hline BS15 & succinate & $1.8 \mu \mathrm{M}$ cam & 4 & $16804,11418,15001,8065$ \\
\hline BS15 & succinate & $2.7 \mu \mathrm{M}$ cam & 4 & $7051,7901,13369,7741$ \\
\hline BS15 & succinate & $4.2 \mu \mathrm{M}$ cam & 2 & 4782,3132 \\
\hline BS15 & mannose & none & 2 & 4782,3132 \\
\hline BS15 & mannose & $1 \mu \mathrm{M}$ cam & 3 & $5368,9213,8086$ \\
\hline BS15 & mannose & $2 \mu \mathrm{M}$ cam & 4 & $14080,12865,18524,15191$ \\
\hline BS15 & mannose & $3.5 \mu \mathrm{M}$ cam & 3 & $6623,7218,9140$ \\
\hline BS15 & succinate rich & none & 2 & 7861,18963 \\
\hline BS15 & mannose rich & none & 2 & 3346,3387 \\
\hline BS15 & glycerol rich & none & 3 & $4807,3152,4819$ \\
\hline BS15 & glycerol rich & $1 \mu \mathrm{M}$ cam & 3 & $3551,4894,2199$ \\
\hline BS15 & glycerol rich & $2 \mu \mathrm{M}$ cam & 4 & $7821,3332,9554,7973$ \\
\hline BS15 & glycerol rich & $3.5 \mu \mathrm{M}$ cam & 4 & $5786,5143,7059,4910$ \\
\hline
\end{tabular}

Table 4: Turbidostat experimental conditions. 


\begin{tabular}{|l|l|l|l|l|}
\hline Strain & Growth medium & Perturbation & Sample size & With initiation size \\
\hline BS45 & succinate & none & 2530 & 506 \\
\hline BS45 & succinate & $2 \mu \mathrm{M}$ cam & 2586 & 534 \\
\hline BS45 & mannose & none & 5478 & 504 \\
\hline BS45 & mannose & $2 \mu \mathrm{M}$ cam & 3375 & 561 \\
\hline BS45 & mannose & $3.5 \mu \mathrm{M}$ cam & 2151 & 553 \\
\hline BS45 & glycerol rich & none & 2355 & 514 \\
\hline BS45 & glycerol rich & $2 \mu \mathrm{M}$ cam & 4743 & 476 \\
\hline BS45 & glycerol rich & $3.5 \mu \mathrm{M}$ cam & 1416 & 198 \\
\hline BS43 & succinate, succinate rich & nutrient shift & 7671 & 1695 \\
\hline SJ1724 & MOPS glucose & none & 4681 & 437 \\
\hline
\end{tabular}

Table 5: Mother machine experimental conditions.

\begin{tabular}{|c|c|c|}
\hline Primer name & Sequence & Location g on genome; ori $=0$ ter $=1$ \\
\hline SJO1152 & CGTTGATAGGAACTAGTAGGGA & ori forward (right arm) \\
\hline SJO1153 & AGCATTTCGCTCAAGGATG & ori reverse (right arm) \\
\hline SJO1232 & GGAATTTCTTTCTCAGGAGAACATTTG & 0.2 forward (right arm) \\
\hline SJO1233 & TCTTTATAACGCAGGCATACGG & 0.2 reverse (right arm) \\
\hline SJO1167 & CAGTTCGAGCGAAACGATAGA & 0.4 forward (right arm) \\
\hline SJO1168 & CGCCACTTTCTCCCTCATAC & 0.4 reverse (right arm) \\
\hline SJO1136 & AGAGATGGGTACGATTGTTTG & 0.73 forward (right arm) \\
\hline SJO1137 & TTGTCCGCAGCAAGTTC & 0.73 reverse (right arm) \\
\hline SJO1138 & TTAACTCGGACATCTTCATCAG & ter forward \\
\hline SJO1139 & CAAGGATCAGGAGCAGTTTAT & ter reverse \\
\hline SJO1140 & CAGTTCTGCGTTTAGCTGTA & -0.74 forward (left arm) \\
\hline SJO1141 & TTCGGTCATTCTTGTGATAGTT & -0.74 reverse (left arm) \\
\hline SJO1175 & TCAAACACATACTTACTCGGATACA & -0.41 forward (left arm) \\
\hline SJO1176 & CTTGCAGGATTTGAAAGGGAAA & -0.41 reverse (left arm) \\
\hline SJO1177 & CATAACCGGGTACTGAGGAAA & -0.22 forward (left arm) \\
\hline SJO1178 & TCGGATTACGGAAGTTGAAGAG & -0.22 reverse (left arm) \\
\hline SJO1179 & CACTGCCAGCATATTGTTTATCG & ori forward (left arm) \\
\hline SJO1180 & GAATGGTTGATCGGTATGGCTA & ori reverse (left arm) \\
\hline
\end{tabular}

Table 6: qPCR primers. 


\section{Mother machine steady-state measurements from all conditions}
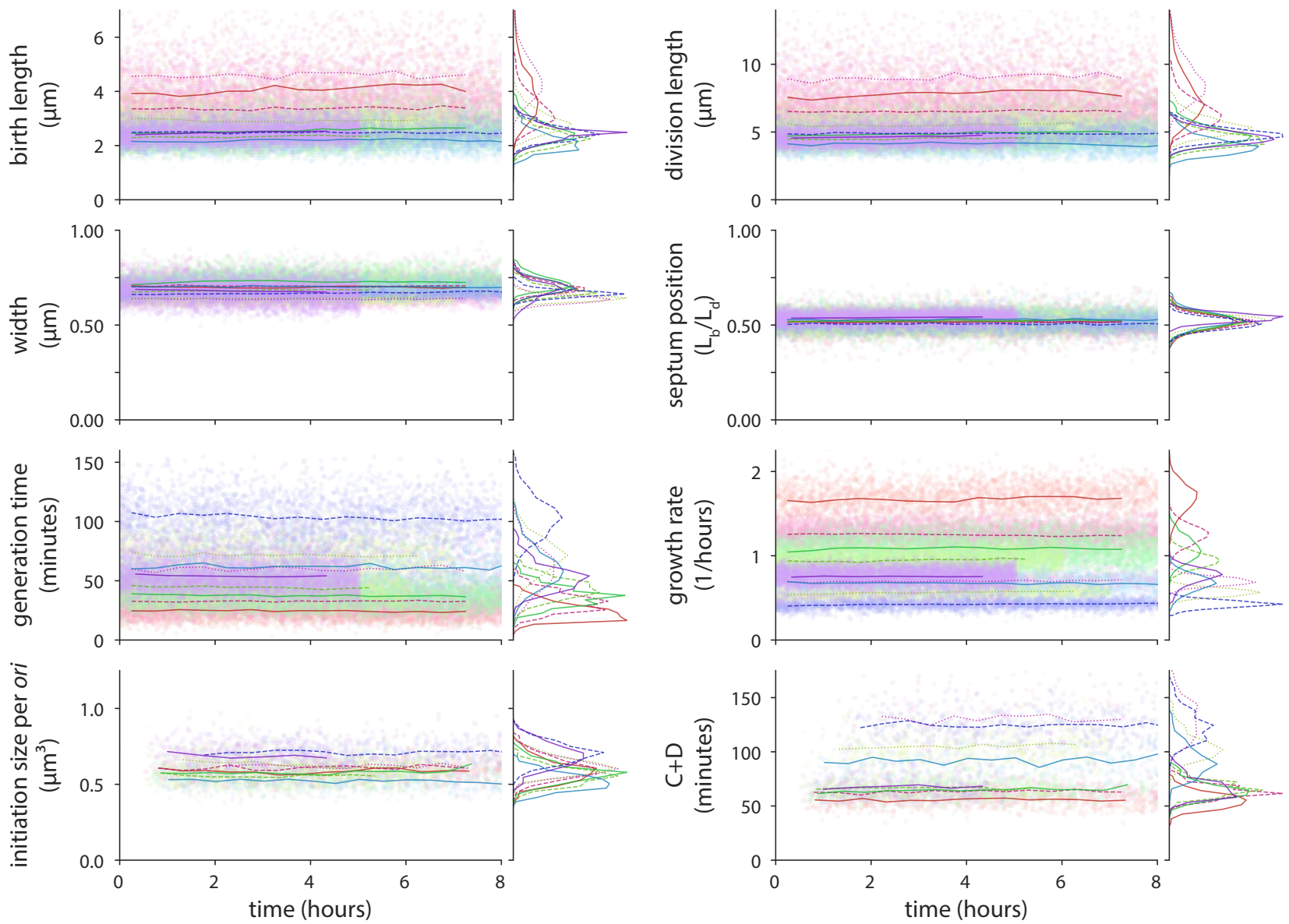

gly+ $0 \mu \mathrm{M}$ cam
gly+ $2 \mu \mathrm{M}$ cam
gly+ $3.5 \mu \mathrm{M}$ cam

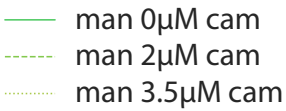

- suc $0 \mu \mathrm{M}$ cam

suc $2 \mu \mathrm{M}$ cam man $3.5 \mu \mathrm{M}$ cam

- E. coli MOPS glc

Extended Figure 1-1: Single-cell steady-state physiological parameters for all conditions. Physiological parameters for all B. subtilis mother machine experimental conditions and one E. coli experiment. Time course is shown with single-cell measurements (scatter points) and 30 minute binned mean (horizontal lines) plotted against the birth time. Multiple consecutive generations are needed to determine initiation size, $\mathrm{C}$ period, and D period, thus a gap exists before those measurements are possible. Single-cell distributions are invariant in time and shown for each condition, sharing the same scale as time course. Colors are as in Figure 1B. Sample sizes are provided in Table 6 . 


\section{A Cell length versus growth rate}

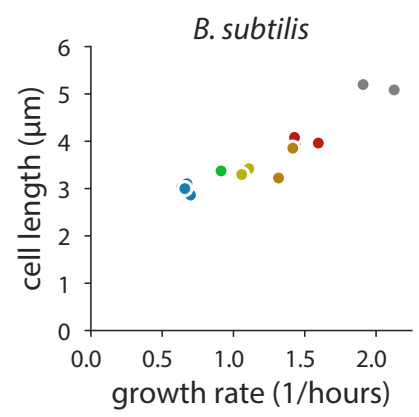

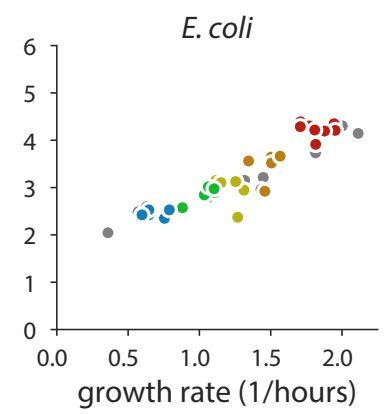

\section{B Cell width versus growth rate}

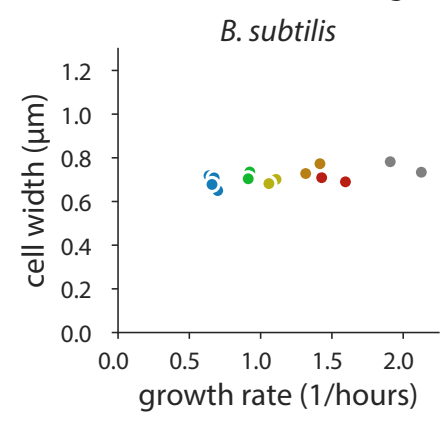

E. coli

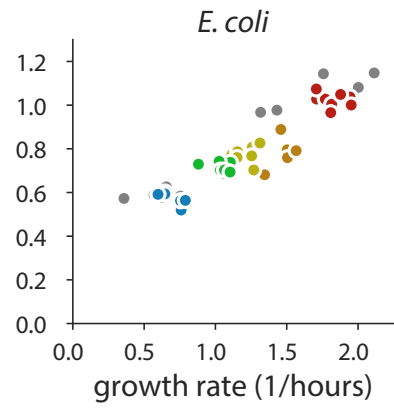

Extended Figure 2-1: Length and width measurements in B. subtilis and E. coli. (A) Cell length in B. subtilis and E. coli increases with growth rate. (B) For $B$. subtilis, width is independent of the nutrient-imposed growth rate. For $E$. coli, width increases with growth rate in a similar manner to length. Colors and conditions are as in Figure 2. E. coli data is from previously published work ${ }^{3}$. 


\section{A Cell length versus growth rate with chloramphenicol}

$$
\text { B. subtilis }
$$

$$
\text { E. coli }
$$
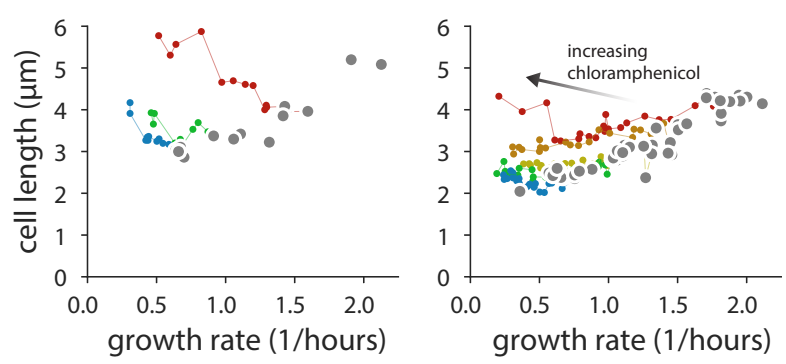

B C period versus growth rate with chloramphenicol

$$
\text { B. subtilis }
$$

E. coli

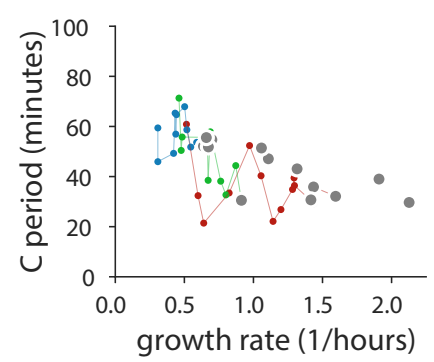

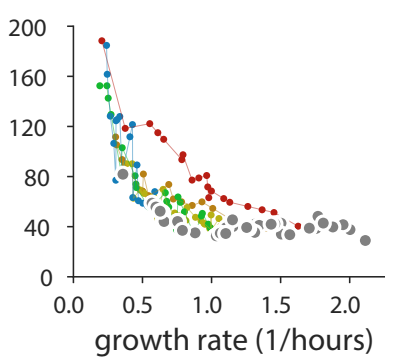

Extended Figure 2-2: Size and C period under translational inhibition in B. subtilis and E. coli. (A) Under translation inhibition due to chloramphenicol, the relationship between cell size and growth rate under nutrient limitation breaks down for both $B$. subtilis and E. coli. (B) The deviation from the nutrient growth law can be attributed to the change in C period in both species under translation inhibition. Lines connect translation inhibition experiments using the same media. Colors and conditions are as in Figure 2. E. coli data is from previously published work $^{3}$. 

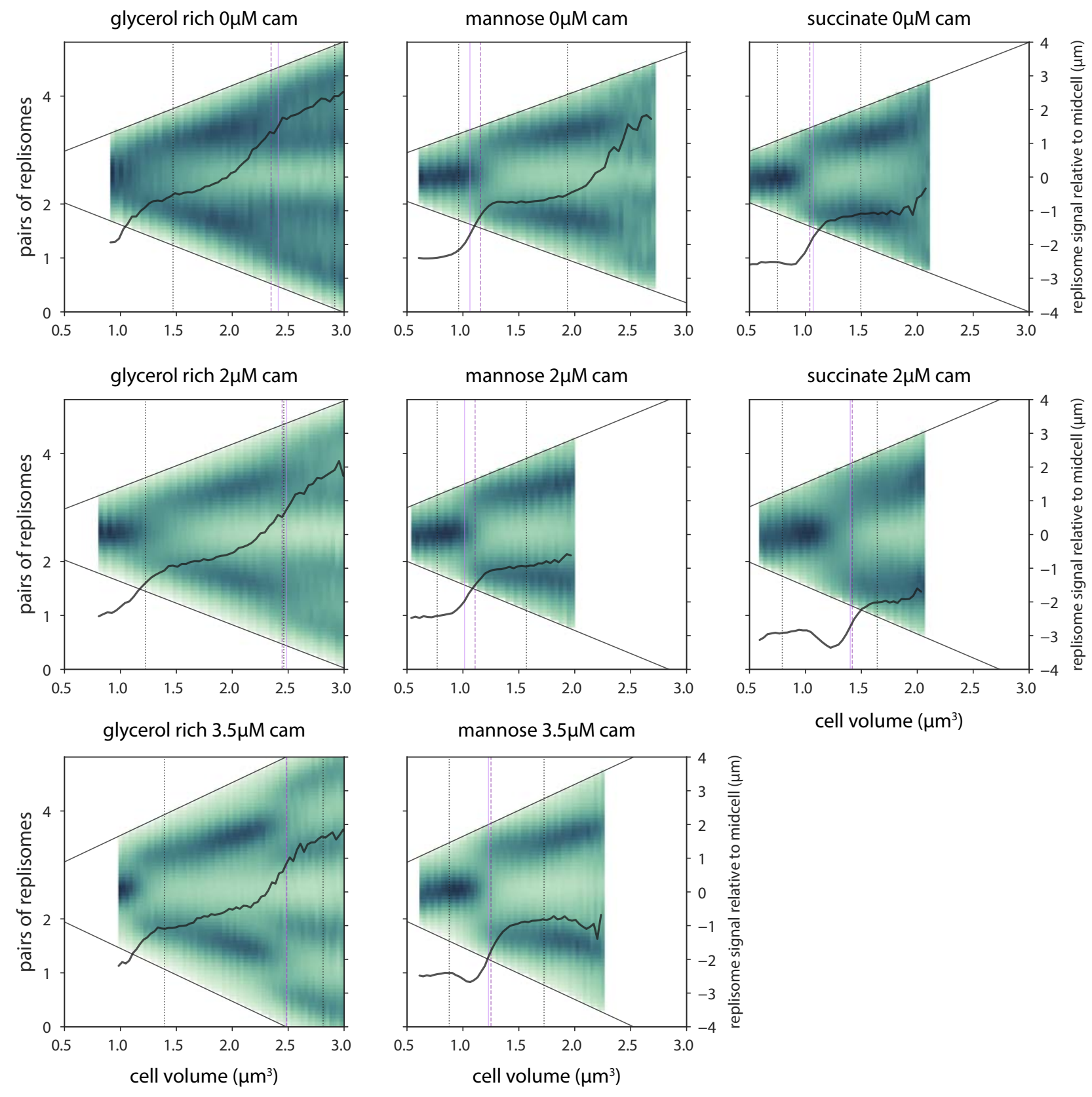

Extended Figure 3-1: Ensemble replisome count and localization for all conditions. Ensemble plots for three media conditions tested with and without translational inhibition. Average pairs of replisomes (thick black line) is plotted against cell volume with consistent scale across conditions. As in Figure 3C, purple vertical lines show the initiation size from the average of single cells (dashed) and the ensemble method (solid). Vertical dotted black lines indicate the average birth and division size. We can calculate the average number of foci for sizes outside the average birth and division length due to cell-to-cell variability (ensemble data is shown at sizes to which at least 50 cells contributed). The average number of foci may be above or below the theoretical number. This is because replisomes transiently dissociate, and a pair of replisomes may be counted as two foci when they are not colocalized ${ }^{24,58,59}$. The normalized DnaN-mGFPmut 2 signal relative to midcell (green background) shows the localization of replisomes over the cell cycle, with the diagonal solid black lines indicating the cell periphery. Termination and replication initiation are often synchronous and correspond to bifurcations in the localization pattern. 

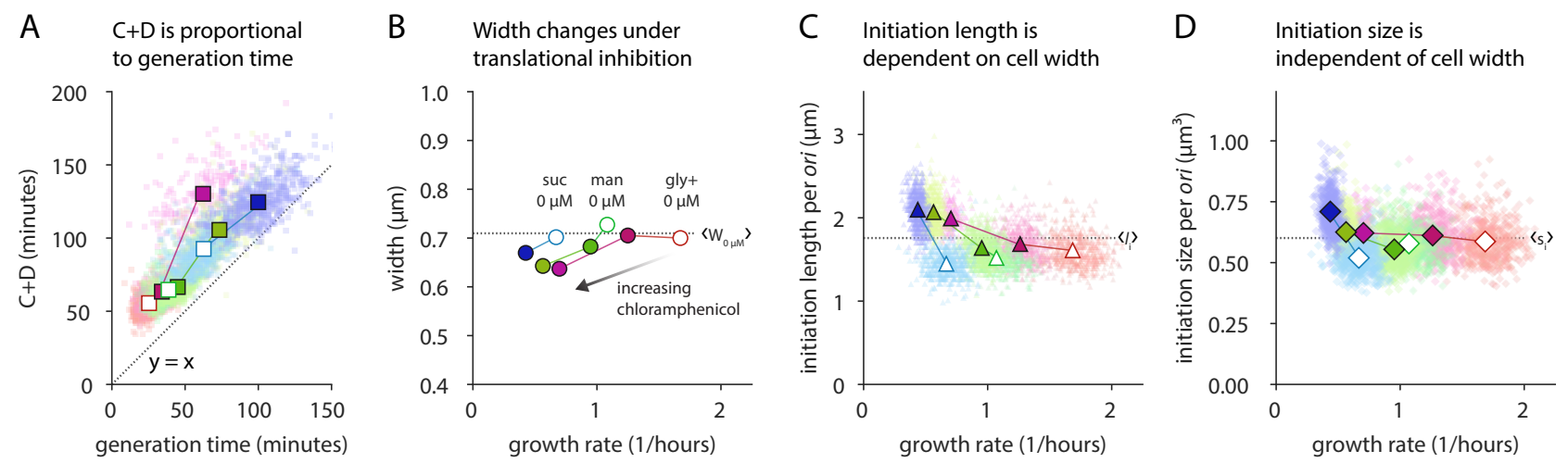

Extended Figure 4-1: B. subtilis cell cycle and initiation size behavior. (A) C+D is proportional to generation time in $B$. subtili when the generation time is modulated by nutrient condition or translational inhibition. (B) Cell width under translational inhibition decreases as compared to the average width without inhibition, $\left\langle\mathrm{W}_{0 \mu \mathrm{m}}\right\rangle$ (dotted black line). (C) Initiation length increase with width under translational inhibition. Mean initiation length per ori $\left\langle\mathrm{L}_{i}\right\rangle$ shown as dotted black line. (D) Initiation size from Figure $4 \mathrm{~A}$ reproduced for comparison. In all plots, colors are as in Figure 4, where lines connect the same growth media with and without chloramphenicol. Scatter points are single-cell data and solid symbols are population averages. 


\section{A Division adderness}

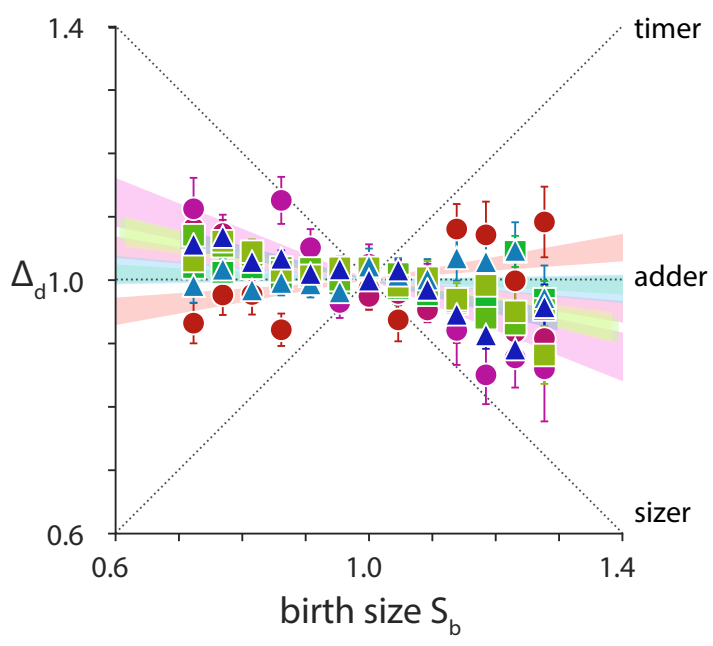

\section{B Initiation adderness}

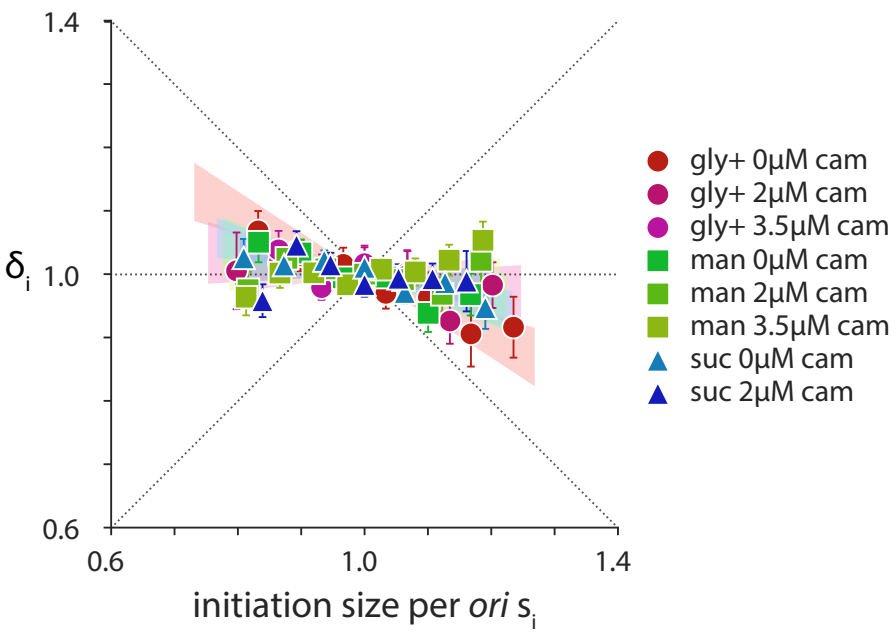

Extended Figure 4-2: B. subtilis is an initiation and division adder. (A) In steady-state growth under nutrient limitation or translational inhibition, B. subtilis $\Delta_{\mathrm{d}}$ is not strongly correlated with the $\mathrm{S}_{\mathrm{b}}$, consistent with the adder principle. Theoretical correlation between $\Delta_{\mathrm{d}}$ and $\mathrm{S}_{\mathrm{b}}$ for the timer, sizer, and adder models of size homeostasis are shown as dotted lines ${ }^{6}$. Symbols are binned data and error bars are standard error of the mean. Shaded wedges are the $95 \%$ confidence interval of a linear regression line fit to the underlying data. Data are rescaled by their respective means. (B) B. subtilis is an initiation adder such that $\delta_{\mathrm{i}}$ is uncorrelated with $\mathrm{s}_{\mathrm{i}}$. However, in the fastest growth condition, added initiation size per ori behaves sizer-like. 
A Single-cell behavior during nutrient shift-up and shift-down

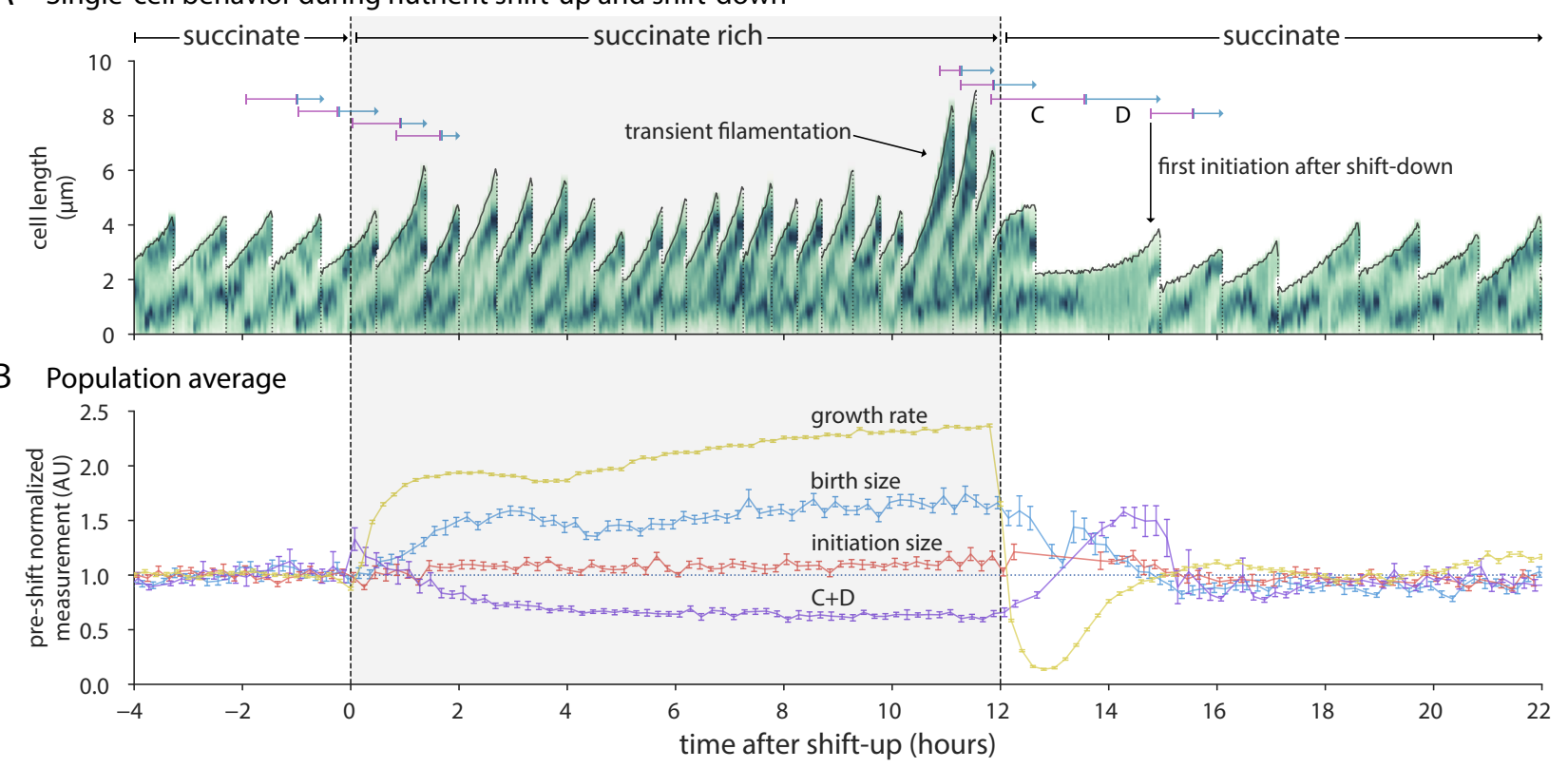

Extended Figure 5-1: Initiation size is invariant during shift-up and shift-down. (A) Representative lineage trace for cells undergoing shift-up at time zero followed by shift-down 12 hours later. Note that this particular trace exhibits transient filamentation before and unrelated to shift-down. (B) Population average behavior for all cells. Mean lines are calculated as in Figure 5, except that the measurements are normalized by their respective mean in the 4 hours before shift-up. Additionally, birth size is plotted against the birth time and $\mathrm{C}+\mathrm{D}$ is plotted against the corresponding division time. Upon shift-up, growth rate immediately increased, simultaneously resulting in an increase in birth size. $\mathrm{C}+\mathrm{D}$ proportionally decreased. After shift-down, all parameters return to their pre-shift-up average. Despite complex dynamics in these parameters during nutrient shifts, the initiation size showed less than a $10 \%$ change during the entire time course. $n=7,671$ cells $(1,695$ with initiation size and $C+D)$. 
A B. subtilis physiological parameter distributions

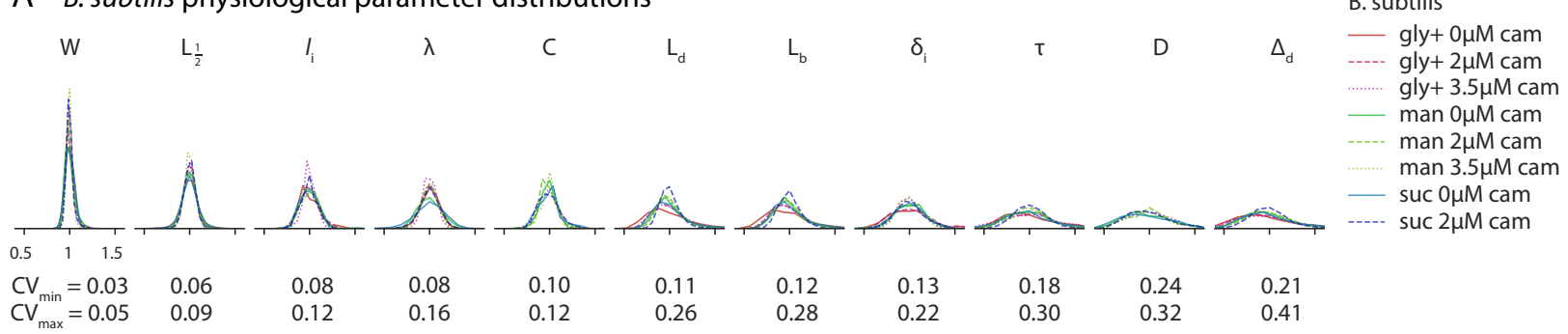

B E. coli physiological parameter distributions

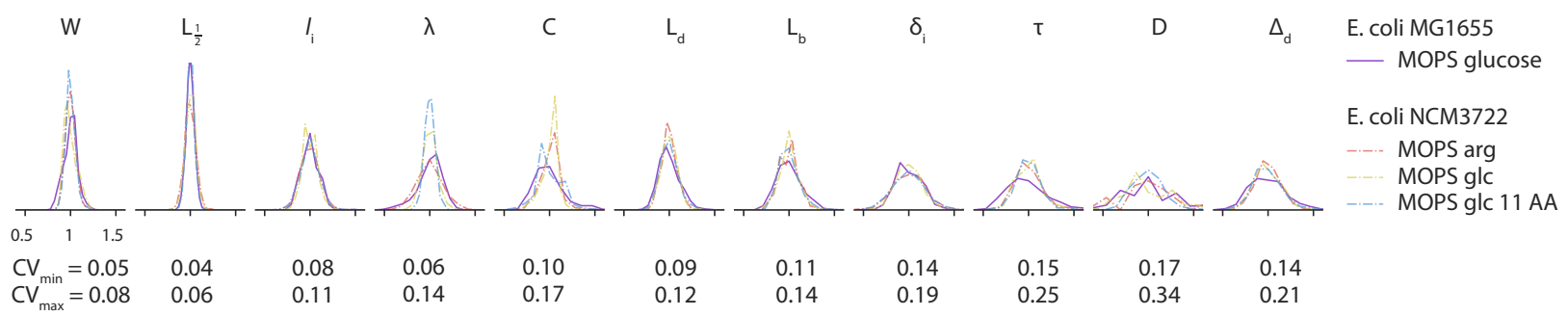

Extended Figure 6-1: Normalized physiological parameter distributions for all conditions. (A) B. subtilis parameter distributions from perturbation experiments are commensurate with nutrient limitation conditions. C period has a smaller CV than D period. (B) In $E$. coli, the $\mathrm{CV}$ of $\mathrm{C}$ period is smaller than $\mathrm{D}$ period. The $\mathrm{CV}$ of $\mathrm{C}+\mathrm{D}$ is smaller than each individually as they are inversely related. Data from E. coli NCM3722 grown in MOPS arginine (arg), glucose (glc) and glucose +11 amino acids (glc 11 AA) are from previously published work ${ }^{7}$. 
bioRxiv preprint doi: https://doi.org/10.1101/726596; this version posted August 6, 2019. The copyright holder for this preprint (which was not certified by peer review) is the author/funder. All rights reserved. No reuse allowed without permission.

Unnormalized B. subtilis

physiological parameter distributions for all conditions
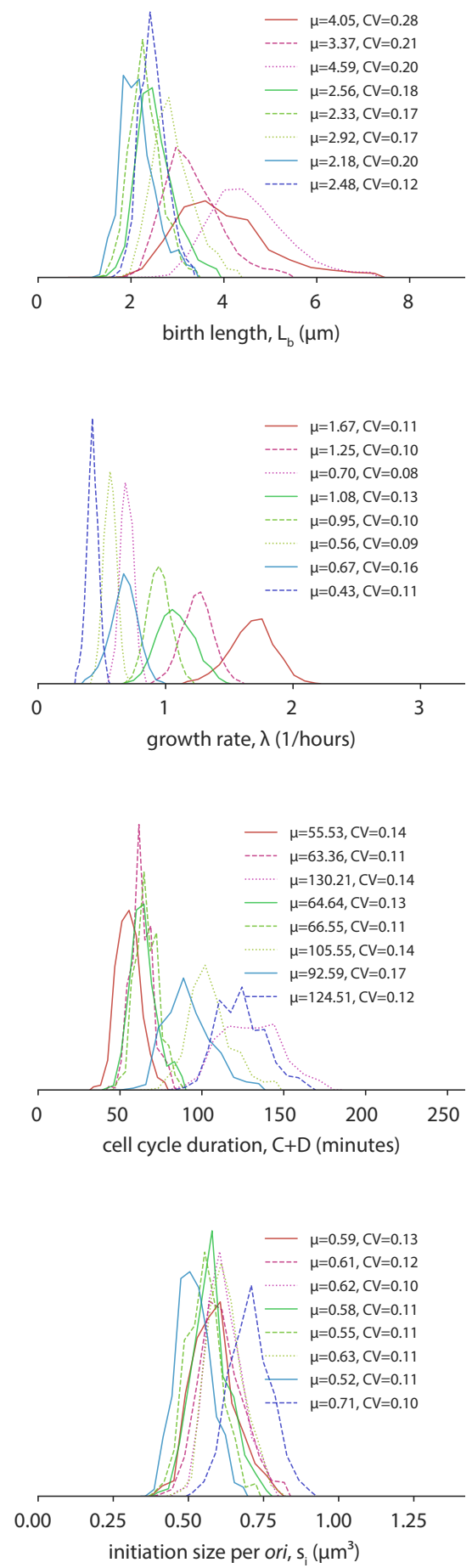
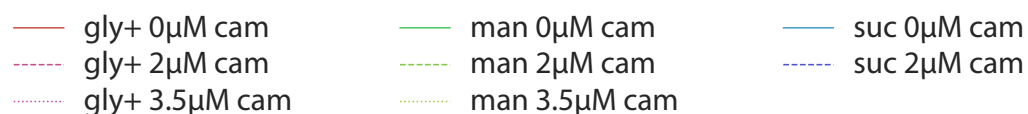

man $3.5 \mu \mathrm{M}$ cam
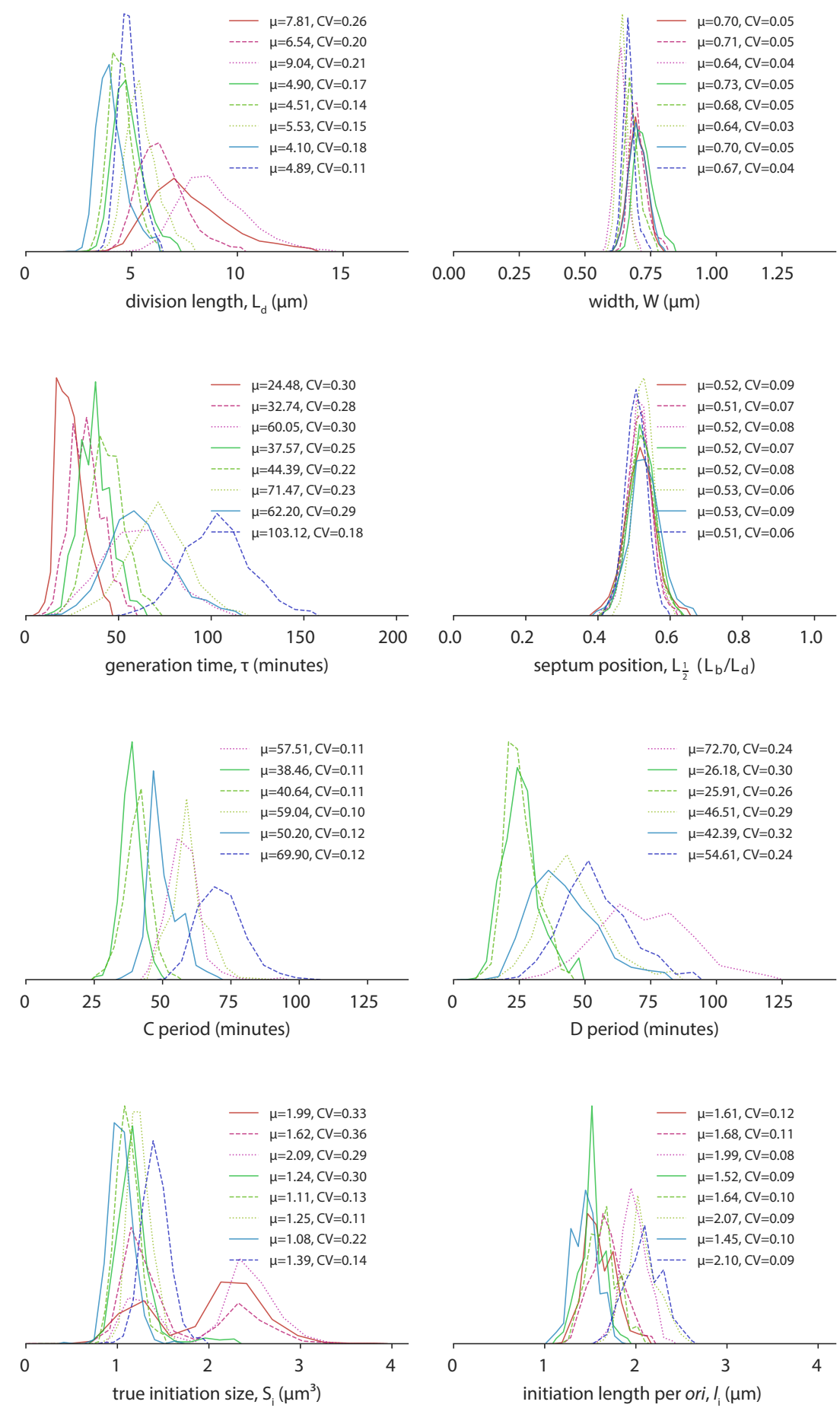

Extended Figure 6-2: Unnormalized physiological parameter distributions for all conditions. B. subtilis physiological parameter distributions for all conditions. Mean $(\mu)$ and CV are presented in the legends. True initiation size $S_{\mathrm{i}}$ is the size at initiation not corrected for the number of ori. For conditions in glycerol rich, cells may be born with 1 or 2 replicating chromosomes. Initiation size per ori $\mathrm{s}_{\mathrm{i}}$, width, and septum position are the most conserved across growth conditions. 
Normalized cross correlations of physiological parameters for all conditions
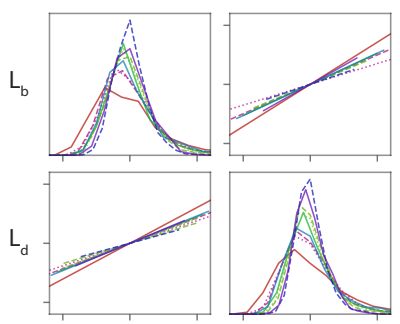

$\Delta_{d}=$
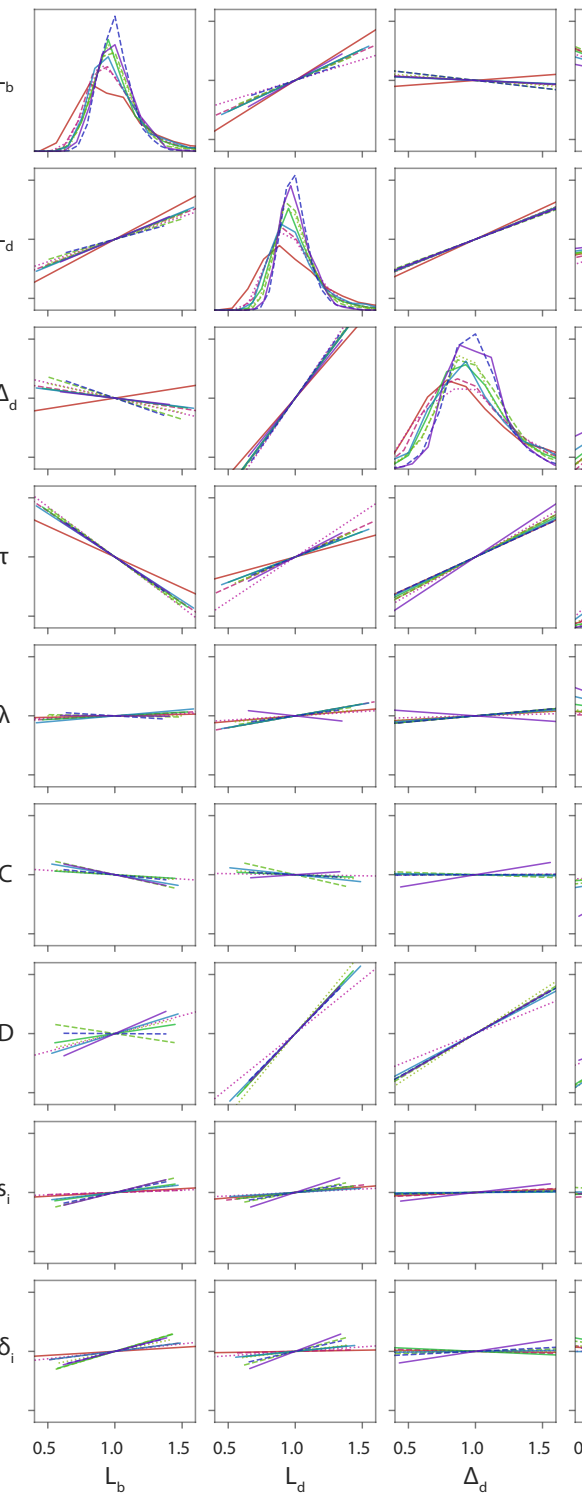
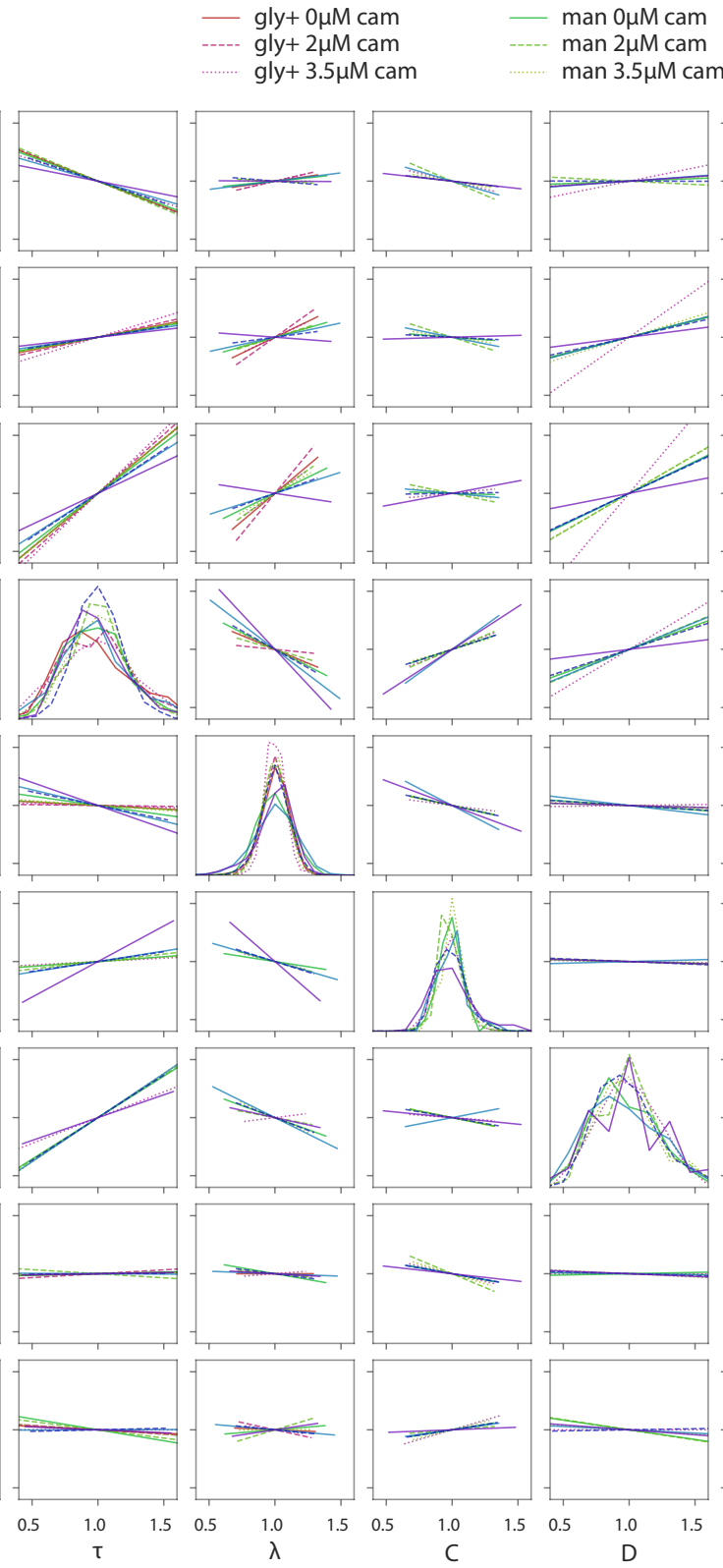
$\operatorname{man} 2 \mu \mathrm{M}$ cam
$\operatorname{man} 3.5 \mu \mathrm{M}$ cam

- suc $0 \mu \mathrm{M}$ cam ----- suc $2 \mu \mathrm{M}$ cam E. coli MOPS glc
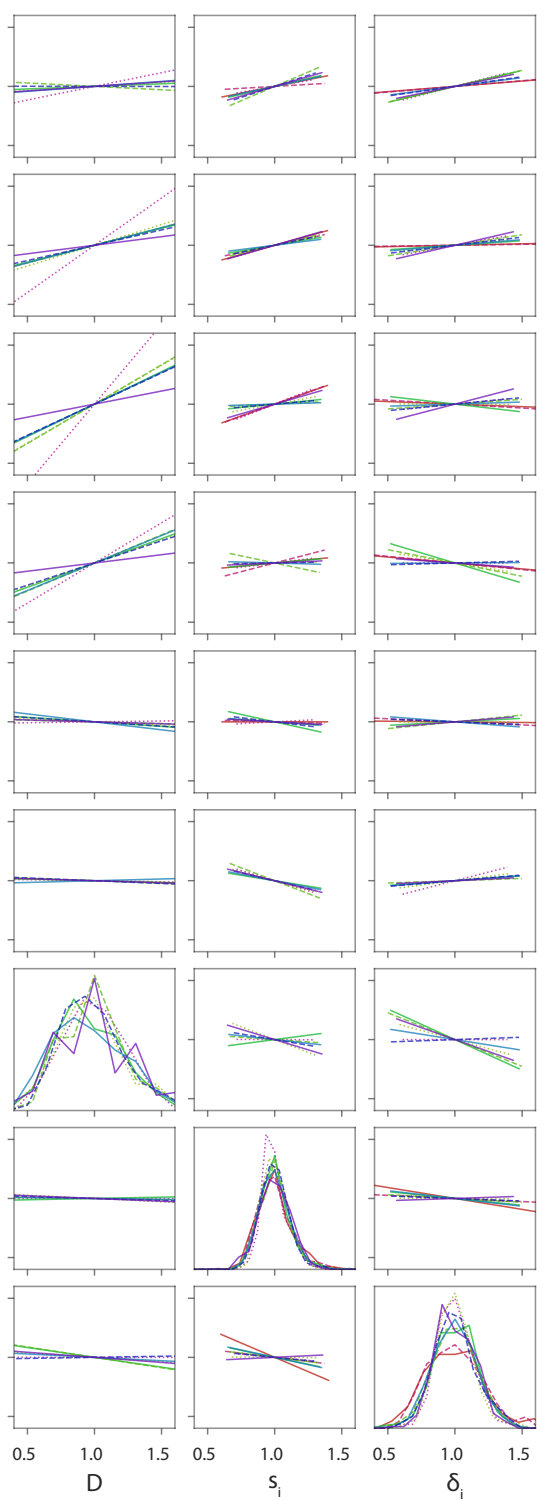

Extended Figure 6-3: Normalized cross-correlations. Normalized cross-correlations for all B. subtilis conditions and one E. coli condition. Lines are linear regression fits to the single-cell data. Symbols are as in Figure 6. Normalized distributions are plotted along the diagonal. 